\title{
MANAGEMENT OF ENDOCRINE DISEASE Therapeutics of vitamin D
}

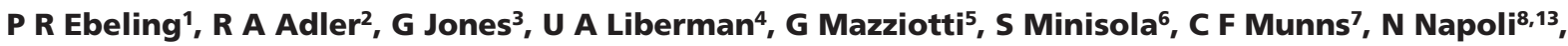 \\ A G Pittas $^{9}$, A Giustina ${ }^{10}$, J P Bilezikian ${ }^{11}$ and R Rizzoli ${ }^{12}$
}

${ }^{1}$ Department of Medicine, School of Clinical Sciences, Monash University, Clayton, Victoria, Australia, ${ }^{2}$ McGuire Veterans Affairs Medical Center and Virginia Commonwealth University School of Medicine, Richmond, Virginia, USA, ${ }^{3}$ Department of Biomedical and Molecular Sciences in the School of Medicine, Queen's University, Kingston, Ontario, Canada, ${ }^{4}$ Department of Physiology and Pharmacology and The Felsenstein Medical Research Center, Sackler School of Medicine, Tel Aviv University, Tel Aviv, Israel, ${ }^{5}$ Endocrine Unit, ASST Carlo Poma, Mantua, Italy, ${ }^{6}$ Sapienza' Rome University, Rome, Italy, ${ }^{7}$ Department of Paediatrics, Westmead Children's Hospital, The University of Sydney, Westmead, New South Wales, Australia, ${ }^{8}$ Unit of Endocrinology and Diabetes, Department of Medicine, Università Campus Bio-Medico di Roma, Rome, Italy, ${ }^{9}$ Division of Endocrinology, Tufts Medical Center, Boston, Massachusetts, USA, ${ }^{10}$ Vita-Salute, San Raffaele University, Milan, Italy, ${ }^{11}$ Division of Endocrinology, College of Physicians \& Surgeons, Columbia University, New York, New York, USA, ${ }^{12}$ Divison of Bone Diseases, Geneva University Hospitals and Faculty of Medicine, Geneva, Switzerland, ${ }^{13}$ IRCCS, Istituto Ortopedico Galeazzi, Milan, Italy

Correspondence should be addressed to P R Ebeling Email peter.ebeling@monash.edu

\begin{abstract}
Objective: The central role of vitamin D in bone health is well recognized. However, controversies regarding its clinical application remain. We therefore aimed to review the definition of hypovitaminosis $D$, the skeletal and extra-skeletal effects of vitamin $D$ and the available therapeutic modalities.

Design: Narrative and systematic literature review.

Methods: An international working group that reviewed the current evidence linking bone and extra-skeletal health and vitamin D therapy to identify knowledge gaps for future research.

Results: Findings from observational studies and randomized controlled trials (RCTs) in vitamin D deficiency are discordant, with findings of RCTs being largely negative. This may be due to reverse causality with the illness itself contributing to low vitamin D levels. The results of many RCTs have also been inconsistent. However, overall evidence from RCTs shows vitamin D reduces fractures (when administered with calcium) in the institutionalized elderly. Although controversial, vitamin D reduces acute respiratory tract infections (if not given as bolus monthly or annual doses) and may reduce falls in those with the lowest serum 25-hydroxyvitamin D (25OHD) levels. However, despite large ongoing RCTs with 21 000-26 000 participants not recruiting based on baseline 250HD levels, they will contain a large subset of participants with vitamin D deficiency and are adequately powered to meet their primary end-points. Conclusions: The effects of long-term vitamin D supplementation on non-skeletal outcomes, such as type 2 diabetes mellitus (T2DM), cancer and cardiovascular disease (CVD) and the optimal dose and serum 25OHD level that balances extra-skeletal benefits (T2DM) vs risks (e.g. CVD), may soon be determined by data from large RCTs.
\end{abstract}

\section{Introduction}

The central role of vitamin $\mathrm{D}$ in bone health is well recognized. However, a series of controversies regarding its clinical application remain. They primarily concern how to define hypovitaminosis $\mathrm{D}$, the skeletal and extra- skeletal effects of vitamin D and the different therapeutic modalities available. To identify the controversial issues, summarize the present state of knowledge and formulate some research questions to answer these controversies,
(C) 2018 European Society of Endocrinology Printed in Great Britain
Published by Bioscientifica Ltd. 
a meeting was held in June 2017, during which the various aspects of vitamin D measurement, its effects and therapeutic applications were reviewed and discussed by international experts in the field. In this paper, we address these issues.

\section{Methods}

This commentary reflects the discussion of a working group that reviewed the current evidence linking bone health and vitamin D therapy. It is based on both narrative and systematic literature reviews, focusing on the most robust clinical evidence, which constituted the search criteria in PubMed.

\section{Vitamin D as a therapeutic agent and its administration}

Questions relating to areas of agreement:

- Is vitamin $\mathrm{D}_{3}$ superior to $\mathrm{D}_{2}$ ? - Pharmacokinetics, clinical data.

- What is the role for 25-hydroxyvitamin $\mathrm{D}$ in replacement and its availability?

- Is there a place for active vitamin D metabolites in treating vitamin deficiency?

- Is daily dosing of vitamin D preferred to larger weekly, monthly or annual doses?

- Does the baseline level of serum 25-hydroxyvitamin D influence the choice and frequency of dose?

- Does BMI or race influence the dose or mode of administration?

- What is the role of fortification in increasing vitamin D?

- How much is too much vitamin D?

- What adverse outcomes are important?

Type and source of vitamin D: metabolites, active forms and analogues

Skin is the major source of cholecalciferol in humans, which is formed after exposure to the ultraviolet $B$ (UVB) wavelength of sunlight. A number of personal and environmental factors reduce the skin production of vitamin D, such as low UVB availability, which is dependent, in part, on latitude, season, time of day and extent of air pollution $(1,2,3)$. Even so, in regions of high UVB availability, a substantial prevalence of hypovitaminosis D has been reported (4). On the other hand, in countries where UVB availability is generally low, such as in Scandanavian countries, the use of cod liver oil and food fortification with vitamin D leads to higher levels of 25-hydroxyvitamin $\mathrm{D}$ than would be expected $(5,6)$. Methods to increase vitamin D intake across a given population, including bio-fortification consisting of adding vitamin $\mathrm{D}$ to livestock feeds or UVB-irradiation of mushrooms and baker's yeast are under evaluation $(7,8)$.

For the treatment of hypovitaminosis D, either sun exposure or increased intake of vitamin D-fortified foods may not be sufficient. In these settings, vitamin D supplements should be considered, with various guidelines suggesting either vitamin $\mathrm{D}_{2}$ (ergocalciferol) or vitamin $\mathrm{D}_{3}$ (cholecalciferol) (9). Vitamin $\mathrm{D}_{3}$ seems to be preferred by many experts because of its greater potency $(10,11)$

Interestingly, a meta-analysis of double-blind RCTs document that focused on a dose of vitamin D >480 IU/ day the pooled effect of vitamin $\mathrm{D}_{3}$ on fractures was significantly lower by $23 \%$, while the pooled effect on fractures was not significant with vitamin $\mathrm{D}_{2}$ (12). When vitamin $\mathrm{D}_{2}$ and $\mathrm{D}_{3}$ are considered together, a Cochrane analysis showed a significant decrease in incidence of hip fractures and non-vertebral fractures in patients treated with vitamin D plus calcium vs no treatment (13).

Regarding vitamin D metabolites in cases of age- or disease-related declines in hepatic and renal function (14), 25-hydroxyvitamin D (calcidiol) can be used, when available. However, calcidiol is not available in the United States. In patients with advanced liver disease in whom the hepatic hydroxylation of vitamin D is impaired, calcidiol would be a logical form because it bypasses that hydroxylation step in the liver (14). It is also a logical form of vitamin D to use in the setting of glucocorticoidinduced inhibition of hepatic 25-hydroxylase. (15). Since glucocorticoids may inhibit not only the hepatic 25-hydroxylation of vitamin $\mathrm{D}$, but also the subsequent 1-hydroxylation step in the kidney, to form active calcitriol, the use of calcitriol has been proposed as a way of bypassing both hydroxylation steps for the treatment of glucocorticoid-induced osteoporosis (GIOP). Indeed, in some clinical studies, active vitamin $\mathrm{D}$ analogues were shown to be more effective than native vitamin $D_{3}$ in terms of bone mineral density (BMD) improvement and reduction of fracture risk in GIOP (16). However, in other studies of GIOP, the effects of native vitamin $\mathrm{D}_{3}$ were comparable with those achieved by active vitamin D analogues (17). Moreover, calcidiol has been proposed for the treatment of hypovitaminosis D in obese patients due to its greater hydrophilic properties, in comparison with vitamin D itself, resulting in a smaller volume of 
distribution and potentially more rapid and effective normalization of serum 25-hydroxyvitamin D values (14). Calcidiol may also be the most preferred form of vitamin $\mathrm{D}$ in cases of fat malabsorption due to a variety of diseases or following bariatric surgery (14). This discussion of advantages of calcidiol over vitamin D itself refers to establishment of vitamin D sufficiency. It does not imply that calcidiol is more effective than vitamin $\mathrm{D}_{3}$ in improving BMD or in decreasing fracture risk, because this point has not been established $(13,14)$.

Evidence of anti-fracture effectiveness, in fact, is weaker for other vitamin $\mathrm{D}$ analogues as compared with vitamin $\mathrm{D}_{3}$, while the risk of side effects is higher (13). Calcitriol $(1,25(\mathrm{OH}) 2$ vitamin D) for example, had no statistically significant effect on hip fracture, non-vertebral fractures or new vertebral deformities $(13,18)$. Two trials suggested that vertebral fractures may be prevented by $1 \alpha$-hydroxycalciferol (alfacalcidol). This analogue, a synthetic active vitamin D compound, hydroxylated at position 1 , can undergo rapid 25-hydroxylation in the liver and thus becomes fully active. While promising, these results were greatly influenced, and perhaps biased, by a quasi-randomized study design (13).

The use of calcitriol or alfacalcidol is recommended only in patients with renal insufficiency and secondary hyperparathyroidism in whom renal $1 \alpha$-hydroxylation of vitamin D is impaired (14). However, even in this clinical setting, there is some evidence that native vitamin $\mathrm{D}$ has the capability to normalize serum parathyroid hormone values, at least when the hyperparathyroidism is not severe (19). Use of the native vitamin D preparation minimizes the risk of hypercalcaemia and hypercalciuria frequently associated with the use of active vitamin D analogues. Interestingly, vitamin $\mathrm{D}_{3}$ has also been shown to improve some extraskeletal end-points, such as proteinuria and anaemia (20).

While food fortification practices are modifying the epidemiological surveys of vitamin D status throughout the world, it is unrealistic to expect that such measures alone will satisfy recommended daily vitamin D requirements across populations. Therefore, the use of vitamin D supplements is often required to ensure normal vitamin D status. The current evidence supports the use of vitamin $\mathrm{D}_{3}$ as a first-line approach for treatment and prevention of hypovitaminosis $\mathrm{D}$, whereas metabolites and active analogues of vitamin D may be used in some specific clinical settings.

To ensure vitamin D adequacy, a daily vitamin D supplement of $400 \mathrm{IU}$ should be provided to all infants and a slightly higher dose (600 IU) (for small children; usually up to the age of 4 years). Similarly, in view of the high prevalence of vitamin D deficiency in older individuals, a daily intake of $600-800 \mathrm{IU}$ is recommended (21). At both ends of the life span, an adequate intake of calcium is also necessary.

\section{Mode of administration and dose}

Supplementation with vitamin D increases serum 25-hydroxyvitamin D levels, but the increment depends upon both body weight and the baseline serum 25-hydroxyvitamin D concentration. Body weight affects the serum 25-hydroxyvitamin D response to both loading and maintenance doses of vitamin $\mathrm{D}$, with larger doses being required. Lower baseline serum 25-hydroxyvitamin D levels are associated with larger increases in serum 25-hydroxyvitamin $\mathrm{D}$ for a given dose of vitamin $\mathrm{D}$.

How body weight affects dosing and serum 25-hydroxyvitamin D level is important to understand, given high prevalence of obesity and reported associations between low vitamin D status and weight-dependent conditions, such as type 2 diabetes mellitus. Compared with people with normal body weight, overweight or obese people have lower 25-hydroxyvitamin D levels and require longer exposure to UVB or higher doses of oral vitamin D supplementation to achieve desired 25-hydroxyvitamin D levels $(22,23)$. It has been postulated that adiposity accounts for the lower 25-hydroxyvitamin D levels seen in overweight/obese individuals due to sequestration of this fat-soluble vitamin D in excess adipose tissue. However, it appears that the difference in 25-hydroxyvitamin D levels is due to extravascular body size (fat and nonfat), although visceral adiposity may contribute more to the inverse association between weight and serum 25 -hydroxyvitamin D levels $(22,23)$. Weight loss results in higher serum 25-hydroxyvitamin D levels (23).

Loading doses The idea of a loading dose is logical, because this could theoretically establish vitamin D adequacy rather quickly and more conveniently. While these are worthy points, it should be noted that at very high loading doses of vitamin $\mathrm{D}$ the efficiency of conversion of vitamin D into 25-hydroxyvitamin D is much lower than when more physiologic doses are used.

The pool of 25-hydroxyvitamin D is estimated at about 160 or $240 \mu \mathrm{g}$ for a subject with serum 25 -hydroxyvitamin $\mathrm{D}$ of $20(50 \mathrm{nmol} / \mathrm{L})$ or $30 \mathrm{ng} / \mathrm{mL}(75 \mathrm{nmol} / \mathrm{L})$, respectively. To replace that pool of 25 -hydroxyvitamin D with oral vitamin $\mathrm{D}$, one should take into account the percentage of intestinal absorption ( 70\%) and the conversion efficiency 
of vitamin D into 25-hydroxyvitamin D. Thus, a total loading dose of 700-1000 $\mathrm{gg}$ or 30-40 000 IU of vitamin $\mathrm{D}_{3}$ should be sufficient to replace near total absence of vitamin $\mathrm{D}$ to normal 25-hydroxyvitamin D concentrations (20-30 ng/mL; $50-75 \mathrm{nmol} / \mathrm{L}$ ). This conclusion is reached on the basis of pharmacokinetic data, but has not been convincingly demonstrated in clinical trials focused on this question.

King et al. (24) found that obese patients had a blunted serum 25-hydroxyvitamin D increment compared with non-obese patients in response to a single oral vitamin $\mathrm{D}_{3}$ dose of 300 000IU after both 6 and 52 weeks. Earlier, van Groningen et al. (25) treated severely vitamin D-deficient subjects with one of several loading regimens: (1) $25000 \mathrm{IU}$ q 2 weeks for 8 weeks (total of $100000 \mathrm{IU}$ ), (2) $25000 \mathrm{IU}$ q week for 6 weeks (total 150000 IU) or (3) 25000 IU q week for 8 weeks (total of 200000 IU). Serum 25-hydroxyvitamin $\mathrm{D}$ was measured at baseline and 10 days after the final dose (the time needed to convert $90-100 \%$ of the $\mathrm{D}_{3}$ dose to 25-hydroxyvitamin D). The three loading regimens caused a dose-related increase in serum 25-hydroxyvitamin $\mathrm{D}$ resulting in mean 25-hydroxyvitamin $\mathrm{D}$ levels of $48.3 \pm 13.0,63.6 \pm 27.5$ and $89.7 \pm 26.9 \mathrm{nmol} / \mathrm{L}$, respectively. The change in 25-hydroxyvitamin D was significantly related to the dose per $\mathrm{kg}$ body weight and is described by the following formula:

$\Delta 25$-Hydroxyvitamin $\mathrm{D}=0.025 \times($ dose per kg body weight $)$

However, they recommended that the formula should not be used in subjects with body weights $>125 \mathrm{~kg}$ (25). No adverse effects in any subject was reported.

The impact of bolus dosing on fall risk is controversial. The question is important given recent evidence that (1) a single large annual oral dose of $500000 \mathrm{IU}$ of $\mathrm{D}_{3}$ increased the risk of falling (26) and (2) in seniors who fell in the last year, monthly oral dosing with $60000 \mathrm{IU}$ (equivalent to 2000 IU/day) caused more falls than monthly oral dosing with $24000 \mathrm{IU}$ (equivalent to $800 \mathrm{IU} /$ day) (66.9 vs $47.9 \%$ fallers, respectively) (27).

Do oral and intramuscular administrations of vitamin D result in equivalent increments in serum 25-hydroxyvitamin D? Romagnoli et al. (28) compared serum 25-hydroxyvitamin D increments after administration of either single oral or intramuscular doses of $300000 \mathrm{IU}$ of $\mathrm{D}_{2}$ or $\mathrm{D}_{3}$ in 32 elderly nursing home residents. The starting serum 25-hydroxyvitamin D levels in the four groups were low, ranging from 7.3 to
$13.3 \mathrm{ng} / \mathrm{mL}$. The 1-month increments in serum 25-hydroxyvitamin $\mathrm{D}$ after treatment with the $\mathrm{D}_{3}$ form were $47.8 \pm 7.3 \mathrm{ng} / \mathrm{mL}$ by the oral route and only $15.9 \pm 11.3 \mathrm{ng} / \mathrm{mL}$ by the intramuscular route. Smaller increments, but similar differences in the two routes of administration were observed in the groups treated with $\mathrm{D}_{2} \quad(15.9 \pm 11.3$ and $5.0 \pm 4.4 \mathrm{ng} / \mathrm{mL}$, respectively). By 60 days however, increments and levels achieved by the two routes were similar. Thus, for loading purposes, the intramuscular route is less effective because of the 2-month lag time in matching the 25-hydroxyvitamin D increment seen with oral administration. For maintenance purposes, more long-term information is needed in order to determine the appropriate dosing frequency.

Maintenance doses The serum 25-hydroxyvitamin D responses to maintenance doses of vitamin $\mathrm{D}$ are also influenced by body weight. Gallagher et al. treated 163 healthy postmenopausal women for 1 year with one of eight doses of vitamin $\mathrm{D}_{3}$ ranging from 0 (placebo) to 4800IU/day (22). The mean starting serum 25 -hydroxyvitamin D level was $39 \mathrm{nmol} / \mathrm{L}$. Obese women (BMI $\geq 30$ ) had 25-hydroxyvitamin D levels that were $17.8 \mathrm{nmol} / \mathrm{L}$ lower than normal weight women (BMI <25), with overweight women falling in between.

\section{Dose frequency - daily, weekly, monthly}

Ish-Shalom et al. (29) reported serial 25-hydroxyvitamin D levels over 2 months of treatment with the same cumulative dose of $\mathrm{D}_{3}$ (equivalent to $1500 \mathrm{IU}$ per day) but given daily, weekly or monthly. The mean levels over the 2-month period were similar although there was slightly more variability with the monthly dosing. Vieth demonstrated that it takes about 3 months for serum 25-hydroxyvitamin D levels to reach steady state after a change in vitamin $\mathrm{D}_{3}$ intake (30), but there is no reason to expect that the conclusion would have been different had the intervention in the Ish-Shalom study continued for the same duration as the study of Vieth. Binkley et al. (31) compared 25-hydroxyvitamin D levels in 64 healthy older adults treated with 1600 IU daily and 50000 IU per month over a 1-year period. Similar serum 25-hydroxyvitamin D levels were achieved with the two dosing frequencies, consistent with the findings of Ish-Shalom.

However, a recent meta-analysis comparing vitamin $\mathrm{D}_{2}$ and $\mathrm{D}_{3}$ supplementation in raising serum 25-hydroxyvitamin $\mathrm{D}$ status showed that vitamin $\mathrm{D}_{3}$ was more efficacious at raising serum 25-hydroxyvitamin D 
concentrations than was vitamin $\mathrm{D}_{2}$. Additionally, when the frequency of dosage administration was compared, there was a significant response to vitamin $\mathrm{D}_{3}$ when given as a bolus dose compared with administration of vitamin $\mathrm{D}_{2}$, but only a non-significant trend was present for daily supplementation (32).

\section{Dietary fat and vitamin D absorption}

Vitamin $\mathrm{D}$ is a fat-soluble vitamin. One study showed the increase in serum 25-hydroxyvitamin $\mathrm{D}$ seen $12 \mathrm{~h}$ after taking a $50000 \mathrm{IU}$ vitamin $\mathrm{D}_{3}$ supplement is about $30 \%$ greater when the supplement is taken with a meal containing fat (33), suggesting vitamin D supplements be taken with a meal containing some fat, whenever practicable.

\section{Variables that influence dosing and levels}

Race: How race affects dosing and the blood 25-hydroxyvitamin D level is important to understand given reported associations of low vitamin $\mathrm{D}$ status and chronic conditions, such as type 2 diabetes, which are prevalent in certain races (e.g. blacks). Compared to Caucasians, blacks have lower total 25-hydroxyvitamin D levels attributed primarily to lower cutaneous biosynthesis. Although absorption and metabolism of oral vitamin D supplementation appears to be the same between blacks and Caucasians, (34) dietary vitamin $\mathrm{D}$ intake may be a stronger determinant of 25-hydroxyvitamin D in blacks than Caucasians. Despite a lower total 25-hydroxyvitamin D level, blacks appear to have a more efficient calcium economy and superior bone mass and lower risk of fractures. Race may also modulate the increased risk of chronic disease (e.g., CVDs, diabetes) associated with low 25-hydroxyvitamin D levels $(35,36)$.

Despite abundant, year-long sunshine in the Middle East, vitamin D deficiency and inadequacy is highly prevalent due, in part, to traditional clothing covering most of the body and the lack of foods rich in, or fortified with, vitamin D. It is highest in women of child-bearing age in the Kingdom of Saudi Arabia at $86.4 \%$ and in elderly Egyptians at $77.2 \%$ (37). A recent multicentre survey of vitamin $\mathrm{D}$ status in China using the LC-MS/MS method showed that 55.9\% of the population had serum 25-hydroxyvitamin D levels $<20 \mathrm{ng} / \mathrm{mL} \quad(<50 \mathrm{nmol} / \mathrm{L})$. Serum 25-hydroxyvitamin $\mathrm{D}$ levels were lower in women than in men, in younger (age 18-39 years) than older (>59 years) individuals and in certain regions. These results emphasize the importance of factors other than latitude (38).

\section{Extra-skeletal effects}

Low vitamin D status, assessed by circulating 25-hydroxyvitamin D levels, has been associated with many acute or chronic medical conditions. One of the most consistent associations is with type 2 diabetes mellitus (T2DM). Longitudinal cohort studies, summarized in recent meta-analyses, have estimated an approximately $40 \%$ risk reduction for incident diabetes in the highest vs the lowest category of 25-hydroxyvitamin D level (39). However, the observational nature of these studies precludes a definitive assessment of cause and effect because reverse causation or residual confounding cannot be excluded. Confounding is especially problematic in this area because blood 25-hydroxyvitamin D level is an excellent marker of good health.

The largest trial of vitamin D supplementation for prevention of T2DM is the Tromso study from Norway (511 white adults with pre-diabetes received 20000 units/ week ( 2900 units/day) vitamin $\mathrm{D}_{3}$ or placebo; follow-up $\sim 3.3$ years for incident diabetes) (40). The risk of diabetes was lower in the vitamin D-supplemented group vs placebo throughout the study; however, the difference was not statistically significant (HR 0.90; 95\% CI 0.69, 1.18). The vitamin $D$ and type 2 diabetes (D2d) study, an ongoing large trial that tests the efficacy of 4000 units/day of vitamin $\mathrm{D}$ on prevention of T2DM in people at high risk, is expected to answer this question.

In relation to T2DM, higher 25-hydroxyvitamin D level is monotonically associated with a lower diabetes risk, suggesting no apparent threshold for benefit (39). However, for non-diabetes outcomes, several observational studies have reported a J-shaped association curve between 25-hydroxyvitamin D levels and important outcomes (e.g., cardiovascular outcomes, mortality) $(41,42)$.

\section{Risks of vitamin D overdose}

Vitamin D contributes to calcium homeostasis by facilitating intestinal calcium absorption and bone resorption. Overdosing can result from endogenous production of the active metabolite, calcitriol, through 1- $\alpha$ hydroxylation in abnormal macrophages encountered in sarcoidosis or other granulomatous diseases. Another cause of endogenous vitamin D excess is its release from fat tissue storage after rapid loss of fat mass. However, the most frequent cause of vitamin D overdosing is exogenous, 
with extremely high doses and consequent production of very high levels of serum 25-hydroxyvitamin D. Clinical expression of vitamin D toxicity includes hypercalcuria and/or hypercalcaemia, with the consequences of calciumcontaining mineral deposits in soft tissues $(43,44)$. Because of the long biological half-life of 25-hydroxyvitamin D, the hypercalcaemia/hypercalciuria can last for several weeks after vitamin D discontinuation.

A recently recognized other potential feature of excessive exogenous vitamin D dosing is the increased risk of fracture and falls observed when large, 'bolus' doses of vitamin D are employed $(26,27,45)$. The adverse consequences of this form of excessive vitamin $\mathrm{D}$ is not accompanied by changes in serum or urine calcium concentrations. The relationship between vitamin $\mathrm{D}$ and a hard outcome like mortality is biphasic, with an increased mortality observed under both vitamin D insufficiency and excess.

\section{Specific therapeutic areas relating to vitamin D}

Vitamin $D$ in primary hyperparathyroidism and hypoparathyroidism

Primary hyperparathyroidism and hypoparathyroidism, classical disorders of parathyroid hormone excess and deficiency, respectively, illustrate well the vital role that vitamin D plays in general calcium homeostasis and in the therapeutics of these two disorders. Under normal circumstances, PTH and vitamin D regulate each other's actions: PTH stimulates renal 1- $\alpha$ hydroxylase activity and, thus, facilitates the production of 1,25-dihydroxyvitamin D. In primary hyperparathyroidism, this enzyme activity is facilitated further leading to levels of active vitamin D that are typically in the upper normal range or frankly elevated (46). In hypoparathyroidism, the absence of PTH leads to relative inactivity of this enzyme, an effect exacerbated by the inhibitory actions of hyperphosphataemia. In hypoparathyroidism, the resulting sluggish renal enzymatic conversion system leads to a deficiency of active vitamin D, despite levels of 25-hydroxyvitamin D that may be normal.

The role of vitamin $\mathrm{D}$ metabolism in primary hyperparathyroidism is further illustrated by the actions of active vitamin D to control PTH. In primary hyperparathyroidism, vitamin D deficiency fuels the processes associated with excessive secretion of PTH, as illustrated by both higher levels of PTH among patients with primary hyperparathyroidism who are also vitamin $\mathrm{D}$ deficient, as well as by histomorphometric and clinical manifestations of the disease that are typically worsened in the setting of coexistent vitamin D deficiency $(47,48,49$, $50,51,52,53)$. Some of the most severe clinical examples of primary hyperparathyroidism occur in countries like India, where vitamin $\mathrm{D}$ deficiency is common $(54,55)$. In countries, like China, where vitamin $\mathrm{D}$ deficiency has become less common, the clinical manifestations of primary hyperparathyroidism have become less severe. In Western Europe and North America, where vitamin D deficiency is regarded to be generally mild when present, primary hyperparathyroidism most often presents as an asymptomatic disease (56). Therapeutic directives related to abnormal vitamin D metabolism in primary hyperparathyroidism and hypoparathyroidism stem from these physiological and pathophysiological considerations.

\section{Primary hyperparathyroidism}

In primary hyperparathyroidism, it is important to ensure vitamin D sufficiency in order to control the component of PTH overactivity due to vitamin D deficiency. Without addressing the controversy over what is the best definition of a normal 25-hydroxyvitamin D level, it seems prudent, with some evidence to back it up, that levels should be aimed at $>30 \mathrm{ng} / \mathrm{mL}(75 \mathrm{nmol} / \mathrm{L})$ in primary hyperparathyroidism $(57,58)$. Treating a hypercalcaemic condition with vitamin $\mathrm{D}$, a calcaemic molecule, leads to caution in choosing the amount of supplemental vitamin $\mathrm{D}$, which should begin with modest amounts. Limited experience with higher doses argues for the more prudent approach of 1000IU daily. The serum calcium should be monitored within a few weeks of instituting or changing the dosage of vitamin D. Vitamin D supplementation results in small increases in spinal BMD in primary hyperparathyroidism (59). There is no rationale for using active vitamin D metabolites in primary hyperparathyroidism.

\section{Points:}

- The three phenotypes of primary hyperparathyroidism each is influenced by vitamin D. In symptomatic hyperparathyroidism (PHPT) with low 25-hydroxyvitamin $\mathrm{D}$, there will be very high PTH and worse disease. Asymptomatic PHPT is associated classically with low 25-hydroxyvitamin D and among those with very low 25-hydroxyvitamin D, PTH levels are higher with some evidence that bone disease might be worse. In normocalcemic PHPT, the diagnosis requires vitamin D sufficiency to rule out secondary hyperparathyroidism. 
- Treatment is aimed at maintaining sufficient vitamin D levels and reducing or eliminating a role for a secondary hyperparathyroidism to add to the primary hyperparathyroid state. Use of vitamin $\mathrm{D}$ should be careful and judicious $(60,61,62)$.

- Guidelines for ascertaining vitamin D sufficiency in PHPT are available $(57,58,62)$.

\section{Hypoparathyroidism}

In hypoparathyroidism, vitamin $\mathrm{D}$ is a mainstay of conventional therapy. In contrast to primary hyperparathyroidism, in which active vitamin $\mathrm{D}$ is not recommended, this metabolite is a key component of virtually all therapeutic regimens. Nevertheless, high levels of 25-hydroxyvitamin D can engage with the vitamin D receptor and therefore act as an active form of vitamin $\mathrm{D}$. Thus, in settings where active vitamin D is not available as a therapeutic, vitamin $\mathrm{D}$, in high doses, can be effective. Therapeutic, daily doses of 1,25-dihydroxyvitamin D (calcitriol) vary widely among patients from as little as $0.25 \mu \mathrm{g}$ to as much as $4 \mu \mathrm{g}$. If the $1-\alpha$ analogue is available, as it is in Europe, the dosing regimen is approximately twice the amount of active vitamin $\mathrm{D}$ because of differences in potency. Active vitamin D is typically given in divided doses. While parental forms of vitamin D, cholecalciferol or ergocalciferol, would not seem to be a rational approach, due to the relative inactivity of the renal $1 \alpha$-hydroxylase in hypoparathyroidism, many clinicians will include a parental form of vitamin $\mathrm{D}$ as part of the therapeutic regimen. The rationale for this approach is based on two points. First, there is some conversion of 25-hydroxyvitamin D (which is produced unimpaired in the liver of these patients) to active vitamin D in hypoparathyroidism. Second, since the liver appears not to be hampered in its ability to metabolize parental vitamin D to 25-hydroxyvitamin D and it further converts that metabolite to others that may have both conventional and unconventional targets, it seems reasonable to aim for a level of 25-hydroxyvitamin $\mathrm{D}$ that is within the normal range. High levels of active vitamin D in hypoparathyroidism cause concern about hypercalciuria, always an issue in this disease. The approach to this therapeutic dilemma has two different outcomes: one emphasizes oral calcium dosing and the other active vitamin $\mathrm{D}$ as the primary conventional modality. With the advent of $\mathrm{rhPTH}(1-84)$ as a registered therapy for hypoparathyroidism, both by the FDA and the EMA, it is possible to reduce the need for supplemental active vitamin $\mathrm{D}$ to physiological equivalents or, in a substantial number of patients, to eliminate its need altogether (63).

\section{Points:}

- Vitamin D metabolism is abnormal in hypoparathyroidism because PTH is an important facilitator of vitamin D activation and it is deficient or absent in this disease.

- The low turnover state is defined, in part, by the combination of low vitamin D and PTH.

- Densitometric observations of increased bone mass are due to the low turnover state.

- With conventional therapy, amounts of active and parent vitamin D required to maintain asymptomatic serum calcium levels can be very high. Such chronically high intake of parent and active vitamin D presents a threat of target organ and ectopic calcium-phosphate deposition.

- The target for serum calcium levels, measured after an overnight fast, should be in the low normal range to avoid hypercalciuria and calcium-phosphate deposition.

- Treatment with rhPTH(1-84) substantially reduces the need for active vitamin D in many patients and in some cases eliminates any need for active vitamin D.

\section{Bariatric surgery}

Bariatric surgery procedures for obesity (64) can be narrowly classified in three groups: restrictive (laparoscopic-adjusted gastric bending and sleeve gastrectomy), malabsorptive (Roux-en-Y gastric bypass and biliopancreatic diversion) or a combination of the two (65). These procedures have the potential to interfere with the achievement of optimal vitamin D status, independent of the threshold suggested to define it (66). Indeed, both the reduction of absorptive area of the small intestine and/or the modified delivery of pancreatic secretions and bile salts lead to decreased vitamin $\mathrm{D}$ absorption. It is also noteworthy that obese patients are often vitamin $\mathrm{D}$ insufficient under basal conditions due to a number of factors including sequestration of vitamin $\mathrm{D}$ by adipose tissue and reduced mobility with limited sun exposure (see discussion above) (67).

From studies attempting to establish the optimal dosing regimen for vitamin $\mathrm{D}$ repletion after bariatric surgery, it is difficult to draw firm conclusions, mainly because of different doses and vitamin $\mathrm{D}$ preparations employed and the different assays utilized for measuring 25-hydroxyvitamin D. The impact of various surgical 
procedures is also different. Therefore, information derived from patients undergoing sleeve gastrectomy cannot be simply translated to other surgical procedures. In this context, the Roux-en-Y gastric bypass seems to carry the highest risk of vitamin D deficiency post surgery because it bypasses the small intestine, the primary site of vitamin $\mathrm{D}$ absorption (68). In this respect, the intramuscular route of vitamin $\mathrm{D}$ administration $(69,70)$ may be effective, especially in obese individuals undergoing malabsorptive procedures. Oral 25-hydroxyvitamin $\mathrm{D}$, when available, may be a good solution to restore vitamin $\mathrm{D}$ deficiency in case of severe fat (and vitamin D) malabsorption. Apart from vitamin D deficiency, intestinal calcium absorption may be severely impaired even after restoration of normal vitamin D status (71).

There is a need for studies defining unanswered research questions in obese patients undergoing bariatric procedures (see below). These surgical interventions also represent a threat for skeletal health with an increased fracture risk (72).

\section{Chronic kidney disease}

Almost all healthy adults experience an age-related decline in renal function. Chronic kidney disease (CKD) is one of the most common problems encountered in internal medicine. Most patients have grade 1, 2 or 3 CKD with estimated glomerular filtration rates (eGFR) of $\geq 90,60-89$ and $30-59 \mathrm{~mL} / \mathrm{min}$, respectively. However, as of about 15 years ago, approximately 300000 Americans have more severe kidney disease defined as grade 4 CKD $(15-29 \mathrm{~mL} /$ min) and about 450000 had grade 5 CKD $(<15 \mathrm{~mL} / \mathrm{min})$ (73, 74). CKD-Metabolic Bone Disorder (MBD) occurs in grade 4 and 5 CKD and is characterized by bone (renal osteodystrophy), soft tissue (calcifications) and mineral (calcium, phosphate, fibroblast growth factor-23, calcitriol, sclerostin, Dikkopf-1) abnormalities. Even worse, other pathological end-points of CKD-MBD include increased cardiovascular risk, mortality and fractures.

Recent Kidney Disease: Improving Global Outcomes (KDIGO) guidelines (75) recommend different forms of vitamin D depending upon the level of renal impairment. In patients with $\mathrm{CKD}$, grade 3 , vitamin $\mathrm{D}_{3}$ supplements should be used to correct deficiency, if present. The use of calcitriol and active vitamin $\mathrm{D}$ analogues should be reserved for use in patients with CKD Grades 4 or 5 with severe and progressive secondary hyperparathyroidism. The guidelines suggest that patients with levels of intact PTH progressively rising or persistently above the upper normal limit for the assay be evaluated for modifiable factors, including hyperphosphataemia, hypocalcaemia, high phosphate intake and vitamin D deficiency. Importantly, however, the guidelines state the optimal level of PTH to achieve with PTH-lowering therapy is as yet unknown. In patients with CKD grade 5 (dialysisdependent), and requiring PTH-lowering therapy, the guidelines recommend the use of calcimimetics, calcitriol or vitamin D analogues, or their combination to maintain intact PTH levels of approximately 2-9 times the upper normal limit for the assay.

Recent European Calcified Tissue Society and European Renal Association of Nephrology Dialysis and Transplantation guidelines (76) suggest there is still value in using the actual PTH concentration to differentiate between high and low turnover states in renal osteodystropy. In cases with either lower PTH levels, or low or intermediate levels of a bone formation marker, bone-specific alkaline phosphatase (BSAP), a bone biopsy may be required to exclude causes of low turnover renal osteodystropy, such as adynamic bone disease and osteomalacia. If osteomalcia is seen on bone biopsy, active vitamin $\mathrm{D}$ is recommended.

\section{Idiopathic infantile hypercalcaemia}

Idiopathic infantile hypercalcaemia (IIH) is a rare disorder caused by genetic mutations of CYP24A1 (25OHD ${ }_{3}$-24-hydroxylase) (77) and SLC34A1 (NaPi-IIa cotransporter) (78). In the case of mutations of CYP24A1, the hypercalcaemia is due to the loss of the CYP24A1 enzyme responsible for the multistep catabolism of the side chain of the active form of vitamin $\mathrm{D}, 1,25(\mathrm{OH})_{2} \mathrm{D}_{3}$, and its precursor, 25-hydroxyvitamin $\mathrm{D}_{3}$, which leads to elevations of both of these vitamin $\mathrm{D}$ metabolites in the blood $(77,79)$. The genotyping of these two genes is critical for determining the correct diagnosis in IIH, but is expensive. In this regard, the careful measurement of the main serum catabolite, 24,25-diydroxyvitamin $\mathrm{D}_{3}$ $\left(24,25(\mathrm{OH})_{2} \mathrm{D}_{3}\right)$, can be useful as a screening tool for IIH where it would be anticipated to be either very low or absent. In fact, rapid liquid-chromatography tandem mass spectroscopy (LC-MM/MS) and non-LC-MM/MS assays have detected a small residual amount of $24,25(\mathrm{OH})_{2} \mathrm{D}_{3}$ (80). A ratio of 25-hydroxyvitamin D: $24,25(\mathrm{OH})_{2} \mathrm{D}_{3}$ of $>80$ (normal 5-25) identifies $\mathrm{IHH}$ due to a loss-offunction CYP24A1 mutation (81). In most affected patients, this ratio is $100-150$. Recently, the residual $24,25(\mathrm{OH})_{2} \mathrm{D}_{3}$ activity has been confirmed by extended chromatography, however, another component of this peak, $25,26(\mathrm{OH})_{2} \mathrm{D}_{3}$ was also resolved (82). In the future, 
it is expected that measurement of serum $24,25(\mathrm{OH})_{2} \mathrm{D}_{3}$ will be more widely adopted and the development of a reference method for $24,25(\mathrm{OH})_{2} \mathrm{D}_{3}$ (83) will be critical to allow for interlaboratory comparisons.

\section{Nutritional rickets}

Nutritional rickets (NR), secondary to vitamin D deficiency and/or dietary calcium deficiency, remains a significant global, public health problem despite the availability of supplementation. A recent international consensus document defined NR and its diagnostic criteria and described the clinical management of rickets and osteomalacia (84). Risk factors, particularly in mothers and infants, were ranked, and specific prevention recommendations including food fortification and supplementation were made.

The diagnosis of NR is made on the basis of history, physical examination and biochemical testing and is confirmed by radiographs. Vitamin D deficiency was defined as a serum 25-hydroxyvitamin $\mathrm{D}<12 \mathrm{ng} / \mathrm{mL}$, while a dietary calcium intake of $<300 \mathrm{mg} /$ day was considered deficient for children over 12 months of age and increases the risk of rickets interdependent of serum 25-hydroxyvitamin D levels. Children with radiographically confirmed rickets have an increased risk of fracture, while those with vitamin D deficiency alone do not. Treatment modalities can be summarized as follows:

1. Vitamin D supplementation to prevent NR:

- $400 \mathrm{IU} /$ day $(10 \mu \mathrm{g})$ is adequate to prevent rickets and is recommended for all infants from birth to 12 months of age, independent of their mode of feeding.

- Beyond 12 months of age, all children and adults need to meet their nutritional requirement for vitamin D through diet and/or supplementation, which is at least $600 \mathrm{IU} /$ day $(15 \mu \mathrm{g})$, as recommended by the Institute of Medicine (IOM).

2. Dose of vitamin D and calcium to treat NR:

- The minimal recommended dose of vitamin D is $2000 \mathrm{IU} /$ day $(50 \mu \mathrm{g})$ for a minimum of 3 months.

- Oral calcium, $500 \mathrm{mg} /$ day, either as dietary intake or supplement should be routinely used in conjunction with vitamin $\mathrm{D}$ in the treatment regardless of age or weight.

3. Route of administration and duration of therapy:

- Oral treatment, which more rapidly restores 25-hydroxyvitamin D levels than IM treatment, is recommended.
- For daily treatment, both vitamin $\mathrm{D}_{2}$ and $\mathrm{D}_{3}$ are equally effective.

- When single large doses are used, $\mathrm{D}_{3}$ appears to be preferable compared to $\mathrm{D}_{2}$ because the former has a longer half-life.

- Vitamin D treatment is recommended for a minimum of 12 weeks, recognizing that some children may require longer treatment duration.

Identification and treatment of risk factors are also important to prevent NR. Importantly, dietary practices and nutrient intakes among mothers associated with NR in infants should be corrected. Maternal vitamin D deficiency should be avoided by ensuring that women of childbearing age meet intakes of $600 \mathrm{IU} /$ day recommended by the IOM. Pregnant women should receive $600 \mathrm{IU} /$ day of vitamin $\mathrm{D}$, preferably as a combined preparation with other recommended micronutrients such as iron and folic acid. Early feeding, supplementation and nutrient intake should also be addressed in infants. In addition to an intake of $400 \mathrm{IU} /$ day of vitamin D, complementary foods introduced no later than 26 weeks should include sources rich in calcium. Subsequently, an intake of at least $500 \mathrm{mg} /$ day of elemental calcium must be ensured during childhood and adolescence.

Public health approaches to prevent NR include universally supplementing all infants with vitamin D from birth to 12 months of age, independent of their mode of feeding. Beyond 12 months, all groups at risk and pregnant women should be supplemented. Vitamin D supplements should be incorporated into childhood primary health care programmes along with other essential micronutrients and immunizations, and into antenatal care programmes along with other recommended micronutrients. Fortification of staple foods with vitamin $\mathrm{D}$ and calcium, as appropriate, based on dietary patterns should be a priority, and supported by legislation and appropriately monitored.

\section{Treatment of hereditary vitamin D-dependent rickets (HVDDR) and hereditary calcitriol-resistant rickets}

Two different hereditary deficiencies in vitamin D action were described in the 1960s and 1970s and were named pseudo vitamin D deficiency type I and II or vitamin D-dependent rickets type I and II (85). The first term emphasizes the fact that the clinical, radiological, histological and most of the biochemical features of both diseases are identical to vitamin D deficiency with no history or biochemical evidence of such deficiency, with the exception of an extremely rare form to be 
discussed below. The term vitamin D-dependent rickets reflects the response to treatment of the type I patients, but it is a misnomer for the type II disease, where more than $50 \%$ of the patients do not respond to treatment with any dose of vitamin D or its 1-alpha hydroxylated active metabolites. Based on our current understanding of vitamin D metabolism, action and the elucidation of the molecular and genetic defects in most of these patients, it is suggested to define patients with a defect in the synthesis of 1,25-dihydroxyvitamin D (calcitriol) as hereditary vitamin D-dependent rickets (HVDDR), type I and II, respectively, and patients with a defect in the response of target tissues to calcitriol as hereditary calcitriol-resistant rickets (HCRR) (86).

Both of these diseases are very rare forms of hypocalcaemic rickets, transmitted as autosomal recessive: the patients are homozygotes and the parents obligate heterozygotes for the mutation (87), although there are some isolated cases that seem to be transmitted as incomplete autosomal dominant. In some kindreds, there is a family history of consanguinity, multiple affected siblings and a specific geographical distribution. The clinical, radiological, histological and biochemical data, with the exception of serum levels of vitamin D and its metabolites, are identical to severe vitamin D deficiency; i.e., signs and symptoms of hypocalcaemia and defective mineralization of newly formed organic matrix of bone: in the growing skeleton - rickets and in remodelling bone - osteomalacia.

A notable difference in clinical presentation is that alopecia is present in more than $50 \%$ of patients with HCRR. The alopecia may be obvious at birth, but usually develops during the first months of life and may range from sparse hairs to total alopecia. In one or two patients additional ectodermal anomalies were observed. Serum biochemistry reveals hypocalcaemia, secondary hyperparathyroidism, hypophosphatemia and elevated levels of biochemical markers of bone formation. Serum levels of 25-hydroxyvitamin D are normal to markedly elevated, depending on prior treatment, in HVDDR type I and HCRR, and low to very low in HVDDR type II. Serum calcitriol levels are low to undetectable in both types of HVDDR and elevated to very high in patients with calcitriol resistance (HCRR), depending on prior treatment with vitamin D or its 1- $\alpha$ hydroxylated metabolites.

HVDDR and HCRR are now understood at the gene level $(85,86,87,88,89)$. HVDDR type I is the end result of different defects in the enzyme 25-hydroxyvitamin D 1- $\alpha$ hydroxylase-causing deficiency of calcitriol and its physiological effects. The same mutation was found in different members of the same kindred, but may be shared with additional unrelated kindreds. HVDDR type II is a very rare mutation in the liver enzyme vitamin D 25-hydroxylase, causing deficiency of 25-hydroxyvitamin D, the substrate for the kidney synthesis of calcitriol and, therefore, a deficiency of the active hormonal form of vitamin D, a similar situation to HVDDR type I (90). In HCRR, different mutations were found along the complex cascade of calcitriol physiological action, starting with the specific binding of calcitriol to the vitamin D receptor (VDR), dimerization with the retinoic $\mathrm{X}$ receptor, modulation of binding of the complex to the nucleus, to specific elements of the DNA (vitamin D-responsive element or VDRE), transcription, translation and posttranslational events. Different defects were observed in almost each of these steps leading to severe aberrations in the physiological response of target tissues to 1,25-dihydroxyvitamin D. These studies became feasible with the demonstration that cells originating from tissues easily accessible contain VDRs that are similar, if not identical, to those of classical target tissues. The cells used were mainly dermal fibroblasts grown from skin biopsies and mitogen-stimulated peripheral T-lymphocytes. These cells are used to assess most of the steps in calcitriol action, as well as the molecular defects and a biological response measured mainly by dose-dependent induction of the enzyme 25-hydroxyvitamin D 24-hydroxylase in both target cells or an antiproliferative effect in mitogen-stimulated peripheral T-cells. Up to now, the response in vivo in patients treated with massive doses of 25-hydroxyvitamin $\mathrm{D}$, or calcitriol and its active metabolites, or tested in vitro, was similar if not identical.

Treatment: HVDDR is a disease caused by a failure to produce an active hormone; thus, the most effective way is to ensure replacement therapy by administration of the active hormone - calcitriol and, in the case of HVDDR type I, also the 1- $\alpha$ hydroxylated vitamin D metabolites that are transformed in the liver into calcitriol (88). A complete cure of all clinical, radiological, histological and biochemical aberrations could be achieved and maintained by the administration of physiological replacement doses of calcitriol $(0.25-1.0 \mu \mathrm{g} /$ day $)$ or its active 1-alpha hydroxylated metabolites $(0.5-2.0 \mu \mathrm{g} /$ day $)$ plus calcium supplementation. As is obvious, the 1-alpha hydroxylated metabolites are contraindicated in HVDDR type II, but calcidiol (not available in all countries) will evoke and maintain a good physiological response. Thus, the clinical and biochemical data of patients with HVDDR type II will resemble vitamin D deficiency. The doses have to be adjusted depending on the severity of the defect 
in bone matrix mineralization, age and weight of the patient. There is a need for close and frequent follow-up, especially in the first few months after treatment is initiated, for clinical and radiological signs as well as serum measurement of calcium, phosphorous, PTH, vitamin D metabolites and 24-h urinary calcium excretion. With full remission, the follow-up frequency can be reduced.

Massive doses of vitamin D or 25-hydroxyvitamin D (1000-3000 $\mu \mathrm{g} /$ day or $200-700 \mu \mathrm{g} /$ day, respectively), 100-300 times the recommended daily dose plus calcium supplementation are required to achieve and maintain chemical and biochemical remission in patients with hereditary vitamin D dependent rickets (HVDDR). Based on the above, this approach is not recommended.

In patients with end-organ resistance to calcitriol (HCRR), less than $50 \%$ of affected individuals presented a complete clinical, radiological and biochemical response to treatment with massive doses of vitamin D, 25-hydroxyvitamin $\mathrm{D}$, calcitriol or its 1- $\alpha$ hydroxylated active metabolites (89). These doses cause an increase in the circulating calcitriol levels, up to more than 100 times the upper normal limit.

This remission may be maintained for years, depending on continuous treatment. There are a very few reports of continuous remission, even after stopping the megadoses of calcitriol or vitamin D metabolites. However, as noted earlier, the majority of patients are resistant even to very high doses of whatever vitamin D-related product is used. Calcium and bone homeostasis may be restored in such patients by using very high oral doses of calcium (up to $5-10 \mathrm{~g} /$ day) or intravenous calcium infusions. For example, in one baby, complete remission of the disease and normalization of biochemical aberrations has been achieved by the administration of massive doses of calcium salts, mainly by the intravenous route, $1 \mathrm{~g}$ of elementary calcium given i.v. each night.

To judge if a patient is responding, 3-5 months of treatment is necessary, with the administration of vitamin $\mathrm{D}$ and calcium as discussed above. This duration of treatment also helps in differentiating HCRR from other situations like 'hungry bone syndrome' that may appear on therapy initiation in patients with very severe calcium or vitamin D deficiency. When a patient undergoes a therapeutic trial, there is a need for frequent and close follow-up, to check clinical and radiological signs as well as serum levels of calcium, phosphorous, PTH and vitamin D metabolites to monitor adverse events, responsiveness and compliance. There is no need to carry out a therapeutic trial in patients with HCRR if the in vitro response of target cells, as discussed above, will continue to be identical to the in vivo response to treatment in these patients.

\section{Recent major and ongoing vitamin D RCTs}

Recent major vitamin D RCTs published from 2013 to 2017

A literature search revealed 475 publications from January 1, 2013 to June 12, 2017 (Scopus). In addition, about 3000 vitamin D randomized controlled trials (RCTs) were registered with the ClinicalTrials.gov registry by 2017 . The primary end-points of these published RCTs included the following health outcomes: Frailty and falls, CVD, maternal and infant health, musculoskeletal diseases, type 2 diabetes mellitus, cancer, critical illness, osteoarthritis of the knee, respiratory diseases, infection and immunity.

A summary of findings from major trials (selected on the basis of $>100$ participants and numbers of citations) follows:

Frailty/falls: A 12-month, double-blind trial of 200 ambulatory men and women (mean age 78 years) given monthly $24000 \mathrm{IU}$ cholecalciferol vs $60000 \mathrm{IU}$ cholecalciferol or $24000 \mathrm{IU}$ cholecalciferol and $300 \mu \mathrm{g}$ calcifediol (27). The primary end point (change in Short Physical Performance Battery scores; including gait speed and repeated chair stands time) was no different across groups. Repeated chair stands showed less improvement in the $60000 \mathrm{IU}$ and $24000 \mathrm{IU}+$ calcifediol groups. The secondary endpoint of falls showed an increased percentage of fallers in the $60000 \mathrm{IU}$ and $24000 \mathrm{IU}+$ calcifediol groups (67 and 66\%, respectively, vs $24000 \mathrm{IU}$ group $(48 \% ; P=0.048)$ ). Despite the lack of a control group, these data suggest monthly high doses of vitamin D should be avoided in the elderly and may also have implications for safety reporting in ongoing large-scale RCTs where this dose is also being trialled (e.g. D-HEALTH).

A trial sequential meta-analysis of 20 trials $(n=29535)$ (91) showed the effect estimate for vitamin D with or without calcium on falls does not alter the relative risk by $\geq 15 \%$. In a sensitivity analysis using a relative risk reduction of $10 \%$, the effect estimate also lay within the futility boundary. Subsequent analyses using a risk reduction threshold of $15 \%$, showed no effect in trials of vitamin D supplementation (16 trials, $n=22$ 291) and in trials of vitamin D with calcium (6 trials, $n=9919)$. Unfortunately, this meta-analysis also included two trials using high annual bolus doses of vitamin $\mathrm{D}$, which were associated with an increased falls risk and are no longer recommended. In an older Cochrane review of 159 trials 
with 79193 participants, vitamin D did not reduce rate of falls (RR 1.00, 95\% CI 0.90-1.11; 7 trials; 9324 participants) or risk of falling (RR $0.96,95 \%$ CI $0.89-1.03 ; 13$ trials; 26747 participants), but may do so in individuals with lower baseline vitamin D levels (92).

Systolic hypertension: A double-blind, placebocontrolled trial of 159 men and women (mean age 77 years) with vitamin $\mathrm{D}$ deficiency and baseline systolic blood pressure (SBP) $>140 \mathrm{mmHg}$ at baseline given 100 000 IU cholecalciferol at baseline, and at 3, 6 and 9 months (93). The change in SBP was not different $(-0.7 \mathrm{mmHg}(95 \%$ CI: $-5.2,3.8), P=0.76)$. There was no difference in pulse wave velocity, blood lipids, inflammatory markers or insulin sensitivity. In conclusion, this small negative RCT suggests vitamin D repletion does not reduce SBP.

CVD: A large, double-blind, placebo-controlled trial (ViDAL) enrolled 5108 participants (58\% male; mean age 65.9 years) treated with a $200000 \mathrm{IU}$ loading dose of cholecalciferol followed by monthly $100000 \mathrm{IU}$ doses for a median of 3.3 years (94). Only 25\% of participants were vitamin $\mathrm{D}$ deficient at baseline. Mean baseline 25 -hydroxyvitamin $\mathrm{D}$ was $63 \mathrm{nmol} / \mathrm{L}$, with only $2 \%$ $<25 \mathrm{nmol} / \mathrm{L}$. There was no difference in incidence of CVD between groups $303(11.8 \%)$ vs $293(11.5 \%) ; \mathrm{HR}=1.02$ $(95 \% \mathrm{CI} ; 0.87,1.20)$. The primary study outcome was negative, but this outcome focused on a large number of different CVD outcomes, and it is unlikely vitamin D deficiency could have a benefit for all of them.

Maternal/infant health: A large double-blind, placebocontrolled trial of 1135 women (mean age 30 years) recruited at 14-week gestation were treated with $1000 \mathrm{IU}$ cholecalciferol per day vs placebo (95). The plasma 25-hydroxyvitamin D increased significantly, by $22.9 \mathrm{nmol} / \mathrm{L}$, in the supplementation group, but did not change in the placebo group. The proportion of women with plasma 25 -hydroxyvitamin $\mathrm{D}>50 \mathrm{nmol} / \mathrm{L}$ increased from 36.5 to $83.4 \%$ in the supplementation group. There were no differences in BMC, BMD, lean mass or fat mass in infants at birth. However, vitamin D prevented winter and spring declines in plasma 25 -hydroxyvitamin D. The season of birth influenced the effects of vitamin D on BMC at birth, resulting in increases in BMC from 57 to $64 \mathrm{~g}$ in babies born in winter. In conclusion, this study showed a stratified approach to vitamin D supplementation in pregnancy is useful. However, a larger dose of $2000 \mathrm{IU} /$ day may result in a larger proportion of women achieving vitamin D sufficiency. Prevention of the gestational reduction in 25-hydroxyvitamin $\mathrm{D}$ in women who deliver in winter could improve BMC of the baby; however, further studies are required to confirm the beneficial skeletal effects of antenatal vitamin D supplementation on offspring.

Musculoskeletal: There were secondary outcomes recorded in the ViDAL Study of 5108 participants (58\% male; mean age 65.9 years) treated with a $200000 \mathrm{IU}$ loading dose of cholecalciferol followed by monthly 100000 IU doses for a median 3.3 years (96). Only 25\% of participants were vitamin D deficient at baseline. Only $2 \%$ $<25 \mathrm{nmol} / \mathrm{L}$ and only 17 hip fractures occurred; no calcium supplements were given. Reported falls were no different: 1312 (52\%) vitamin D vs 1326 (53\%) placebo; HR=0.99 (0.92, 1.07) $P=0.82$. Non-vertebral fractures were also similar; 156 (6\%) vitamin D vs 136 (5\%) placebo; HR: 1.19 (95\% CI: 0.94-1.50) $P=0.15$. However, the interpretation of these outcomes has some limitations. These were secondary trial outcomes; the trial was underpowered to detect differences in falls and fractures, and bolus D dosing was used, which based on recent RCT data in the elderly would not now be recommended in that group.

A recent systematic review and meta-analysis of 33 randomized trials (51 145 community-dwelling participants aged $>50$ years) showed no significant association of either calcium or vitamin D with risk of hip fracture compared with placebo or no treatment (calcium: RR, 1.53 (95\% CI: 0.97-2.42); vitamin D: RR, 1.21 (95\% CI: 0.99-1.47)) (97). Nor was there any significant association of combined calcium and vitamin D with hip fracture compared with placebo or no treatment (RR, 1.09 (95\% CI: 0.85-1.39)). No significant associations were found between calcium, vitamin $\mathrm{D}$, or combined calcium and vitamin $\mathrm{D}$ supplements and incidence of non-vertebral, vertebral or total fractures. These negative findings were not altered by adjusting for the calcium or vitamin D dose, sex, fracture history, dietary calcium intake and baseline serum 25-hydroxyvitamin D. However, this meta-analysis included two trials, which may have adversely affected the outcomes - the RECORD study, a trial of secondary, not primary, fracture prevention and the largest trial (WHI), which used a suboptimal dose of vitamin D (400IU per day), based on the current IOM recommendation.

Body composition: A double-blind, placebo-controlled trial of 218 postmenopausal women (mean age 60 years) recruited with serum 25-hydroxyvitamin D between 10 and $32 \mathrm{ng} / \mathrm{mL}$ were treated with $2000 \mathrm{IU}$ cholecalciferol per day vs placebo for 12 months (98). All participants underwent a diet and exercise weight loss programme. There were no differences in weight loss $(8.2 \%$ vs $8.4 \%$, $P=0.66)$; change in lean mass $(-0.8 \mathrm{~kg} \mathrm{vs}+1.1 \mathrm{~kg}, P=0.53)$; appendicular lean mass both groups (both $-0.1 \mathrm{~kg}$, $P=0.11)$ and no difference in upper body strength $(-0.9$ 
lbs vs $-3.6 \mathrm{lbs} ; P=\mathrm{NS})$. However, leg strength significantly decreased in vitamin D-supplemented subjects $(-2.6 \mathrm{lbs}$ vs $+1.8 \mathrm{lbs} ; P=0.03)$, and there was greater spinal bone loss in the vitamin D group $\left(-0.02 \mathrm{~g} / \mathrm{cm}^{2} \mathrm{vs}-0.01 \mathrm{~g} / \mathrm{cm}^{2}\right.$; $P=0.01)$. Although a greater magnitude of change in serum 25-hydroxyvitamin $\mathrm{D}$ was significantly associated with greater weight loss in the vitamin D group $(P=0.03)$, a greater increase in 25-hydroxyvitamin $\mathrm{D}$ was not significantly associated with any other outcome. Vitamin D supplementation resulted in greater rates of spinal bone loss and decreases in leg strength, which was unanticipated; however, the biological significance of these small changes is unclear.

Diabetes mellitus: A double-blind, placebo-controlled trial was conducted in 275 adults with type 2 diabetes mellitus, serum HbA1c $\leq 8.0 \%$ and stable for 3 months (99). Exclusion criteria included an eGFR $\leq 30 \mathrm{~mL} / \mathrm{min} / 1.73 \mathrm{~m}^{2}$. They were treated with $50000 \mathrm{IU}$ cholecalciferol monthly for 6 months vs placebo. There was no change in the primary end point, HbA1c $(\beta=0.4(-0.6,1.5) P=0.42)$. No significant differences were seen in other indicators of glycaemic control and anthropometric variables. There was no effect of vitamin D on diabetes control in this short duration trial. Confirmation is required by larger trials of longer duration (D2d).

Cancer: In a large double-blind, placebo-controlled trial of 2303 postmenopausal women (mean age 65 years), subjects were treated with $2000 \mathrm{IU}$ cholecalciferol per day and $1500 \mathrm{mg}$ per day of calcium or placebo for 4 years (100). A new diagnosis of cancer was confirmed in 45 (3.9\%) in the vitamin D group and $64(5.6 \%)$ in placebo (difference, $1.69 \%(-0.06 \%, 3.46 \%) ; P=0.06)$. KaplanMeier incidence over 4 years was $0.042(0.032-0.056)$ in vitamin $\mathrm{D}$ vs 0.060 (0.048-0.076); $P=0.06$. Although the study was negative, it certainly suggests a trend for vitamin $\mathrm{D}$ to reduce cancer, which needs to be confirmed in ongoing, larger RCTs (D-HEALTH, VITAL).

Acute respiratory infections: Although an earlier, smaller meta-analysis of 15 trials including 7053 individuals did not show an effect of vitamin $\mathrm{D}$ in reducing acute respiratory tract infections (101), a recent larger metaanalysis of 25 eligible RCT did show a decrease (total of 11321 participants, with individual patient data obtained for 10933 (96.6\%)) (102). Vitamin D reduced the risk of acute respiratory tract infections (RTIs) among all participants (OR=0.88, 95\% CI: $0.81-0.96 ; P<0.001)$. Protective effects were seen in those receiving daily or weekly vitamin $\mathrm{D}$ without additional bolus doses ( $\mathrm{OR}=0.81,95 \%$ CI: 0.72-0.91), but not in those receiving bolus doses. Protective effects were greatest in those with baseline serum 25-hydroxyvitamin $\mathrm{D}<25 \mathrm{nmol} / \mathrm{L}$ $(\mathrm{OR}=0.30,95 \%$ CI: 0.17-0.53) than in those with baseline 25 -hydroxyvitamin $\mathrm{D} \geq 25 \mathrm{nmol} / \mathrm{L}(\mathrm{OR}=0.75,95 \% \mathrm{CI}$ : $0.60-0.95$; $P$ interaction $=0.006$ ). These data show vitamin D supplementation protected against acute RTI, and patients with severe vitamin D deficiency and those not receiving bolus doses experienced the most benefit from supplementation.

Knee osteoarthritis: In a double-blind, placebocontrolled trial, 413 adults, aged 50-79 years, were treated with $50000 \mathrm{IU}$ cholecalciferol per month or placebo for 2 years (103). Patients had knee pain for the previous 6 months ranging from 20 to 80 (out of 100 on VAS); ACR class of I, II or III and a serum 25-hydroxyvitamin $\mathrm{D}$ of $12.5-60 \mathrm{nmol} / \mathrm{L}$ at baseline. There was no difference in change in WOMAC pain score between groups $(-49.9$ for the vitamin D group vs -35.1 for placebo; betweengroup difference, -14.8 ( -32.5 to 2.9 ); $P=0.10$ ). The change in MRI tibial cartilage volume was not different between groups $\left(-242.6 \mathrm{~mm}^{3}\right.$ vitamin D vs $-301.4 \mathrm{~mm}^{3}$ with placebo (between-group difference, $58.8 \mathrm{~mm}^{3}(-13.9$ to 131.4$) ; P=0.11$ ). Vitamin D supplementation therefore had no effect on either pain score or cartilage volume in patients with knee osteoarthritis.

A double-blind, placebo-controlled trial was performed in 146 adults treated with a $2000 \mathrm{IU}$ cholecalciferol per day, to reach a target level of $36-100 \mathrm{ng} / \mathrm{mL}$ vs placebo for 2 years (104). There were no differences in WOMAC pain score $-0.87(-2.12,0.38) P=0.17$ or function -3.11 ( -6.52 , 0.30) $P=0.07$. There were also no differences in chair stand, $20 \mathrm{~m}$ walk times or in MRI-derived parameters of knee cartilage, including tibial cartilage, femoral cartilage or combined cartilage volumes. This study showed no effect of vitamin D supplementation on pain score or cartilage volumes in patients with knee osteoarthritis.

Two recent systematic reviews $(105,106)$ and metaanalyses of the effects of vitamin D supplementation on knee osteoarthritis, in four RCTs involving 1136 patients, showed vitamin D supplementation of more than 2000 IU vitamin $\mathrm{D}_{3}$ per day resulted in small decreases in the WOMAC pain score and function in patients with knee OA. However, there was no beneficial effect on the prevention of tibial cartilage loss. Therefore, there is currently a lack of evidence to support the use of vitamin D supplementation in preventing the progression of knee $\mathrm{OA}$.

\section{Conclusions}

There is discordance between the findings of observational studies associating vitamin D deficiency with positive 


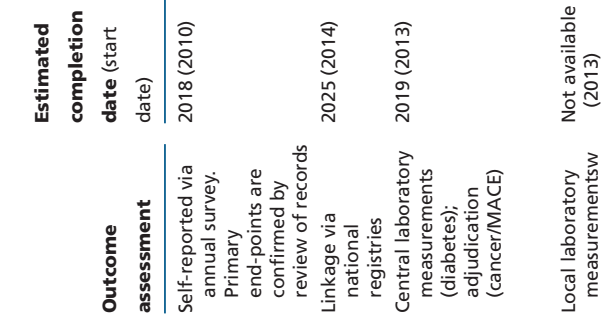

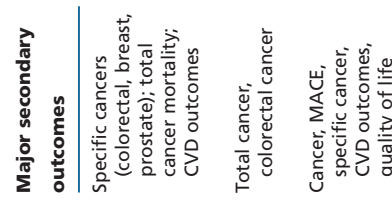

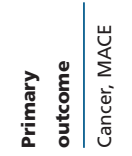

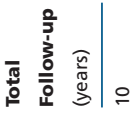

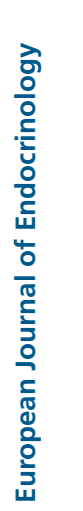

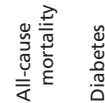

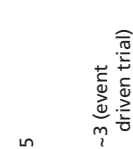<smiles>C[C@H]1[CH]C=C1</smiles>

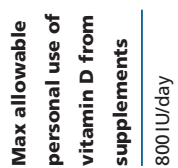

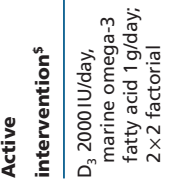

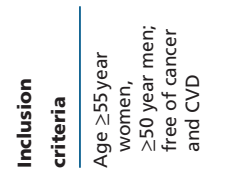

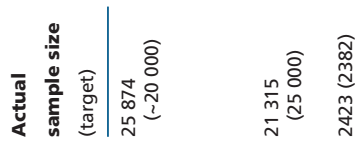

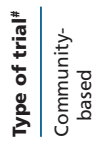

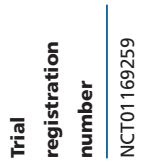

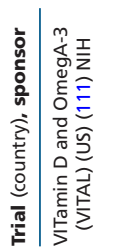

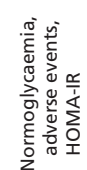

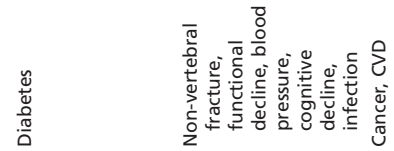

童

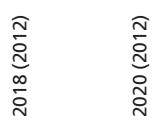

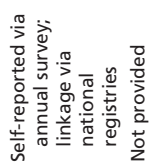

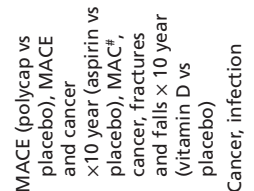

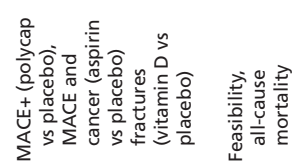

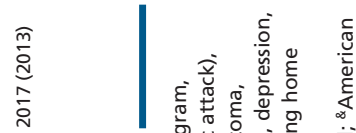

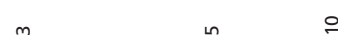

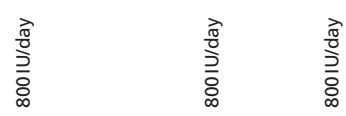

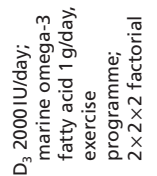

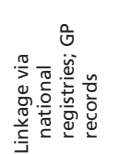

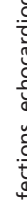

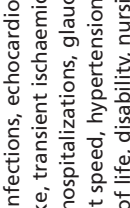

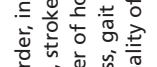

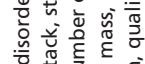

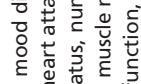

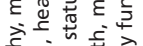

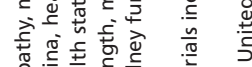

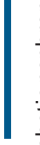

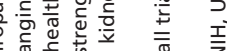

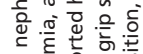

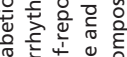

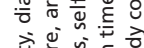

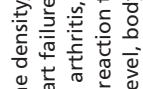

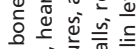

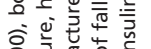

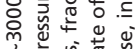

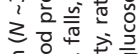

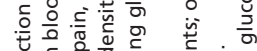

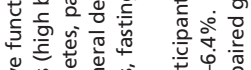<smiles>C1CCCCC1</smiles><smiles>C1CCCC1</smiles>

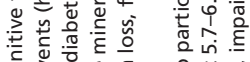

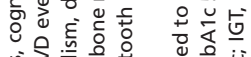

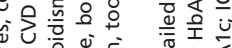

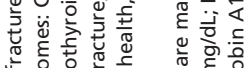

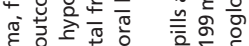

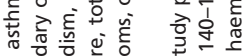

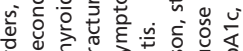

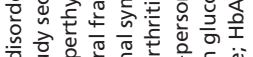

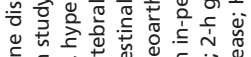

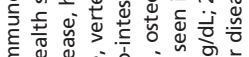

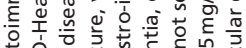

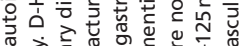

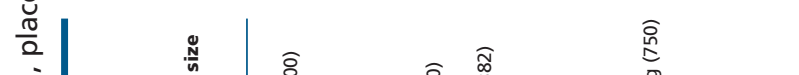
部

暗

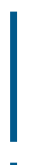

总|

$\stackrel{\substack{n \\ \frac{n}{n}}}{\frac{n}{n}}$
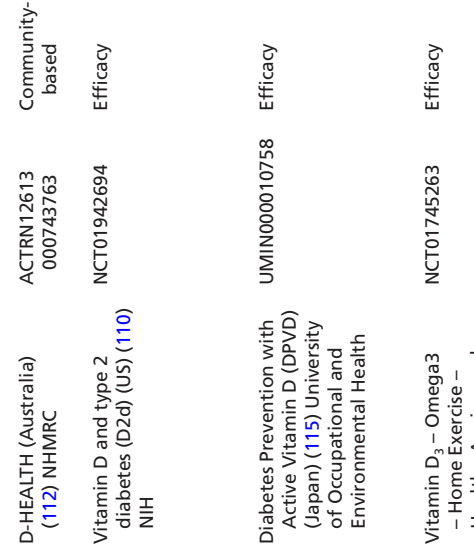
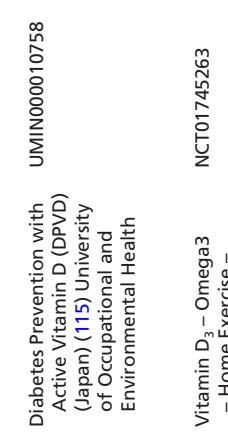

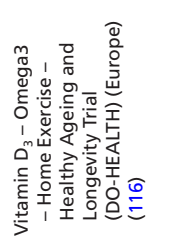

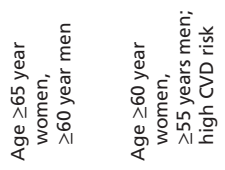

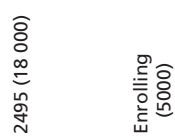

密

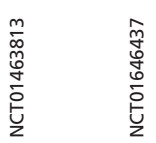

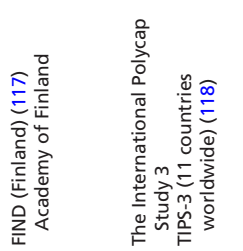

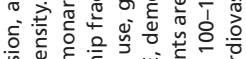

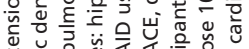

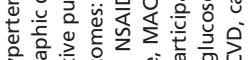

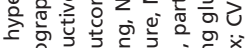

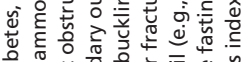

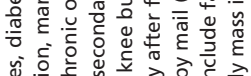

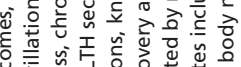
亏亏 守要

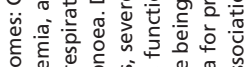

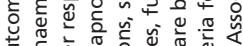

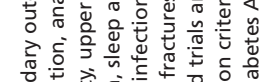


disease outcomes and the findings of RCTs in vitamin D deficiency, which are largely negative to date. This may be due to reverse causality with the illness itself contributing to low vitamin D levels. The results of many RCTs have also been inconsistent. However, overall evidence from RCTs shows vitamin D reduces fractures (when administered with calcium), in the instutionalized elderly, but not in community-dwelling adults $>50$ years (107). Our consensus is that, although controversial (108, 109), vitamin D also reduces acute RTIs (if not given as bolus monthly or annual doses), and may reduce falls in those with the lowest serum 25-hydroxyvitamin D levels. Currently, there is no consistent or conclusive evidence for a positive vitamin $\mathrm{D}$ impact on other diseases or on overall mortality.

\section{Future opportunities}

Vitamin $D$ is a nutrient and any beneficial effects of vitamin $\mathrm{D}$ would be anticipated to be greatest in those with the most severe deficiency (25-hydroxyvitamin $\mathrm{D}<30 \mathrm{nmol} / \mathrm{L}$ or $<12 \mathrm{ng} / \mathrm{mL}$ ). The large ongoing RCTs with 21000 26000 participants, described in the next section, did not recruit based on baseline serum 25-hydroxyvitamin D levels, but will contain a large subset of participants with vitamin D deficiency and are adequately powered to meet their primary end-points.

\section{Ongoing RCTs with vitamin D supplementation}

There are several larger, ongoing, placebo-controlled trials that test the safety and efficacy of vitamin D supplementation on a variety of outcomes (Table 1). There are two general types of trials with different strengths and weaknesses. Efficacy trials (e.g., D2d) (110) place emphasis on optimizing internal validity by evaluating participants in-person and employing rigorous ways to assess outcomes that include laboratory assessment by a central laboratory.

In community-based trials (e.g. VITAL, D-HEALTH) $(111,112)$, the study is conducted 'by mail' and participants are not evaluated in-person. Study pills are mailed to participants living in the community and outcomes are self-reported based on surveys or through search of Electronic Health Records. Community-based studies enrol a very large number of participants at a fraction of the cost of large-scale efficacy trials. However, such studies often have several weaknesses including less than optimal adherence with study treatment, considerable personal use of supplements $(113,114)$ and reliance on self-reported or administrative data to assess outcomes, which may limit accuracy. All trials limit out-of-study personal use of vitamin D; however, given the popularity of vitamin D supplements in the general population, 'contamination' of the intervention by personal use of supplements is a serious concern as the cohort may be sufficiently replete at baseline and throughout the trial.

Many trials (e.g., VITAL, D-HEALTH) $(111,112,115$, $116,117,118,119)$ will conduct analyses for a very large number of secondary outcomes, and the possibility of false-negative results due to multiplicity of testing is also a real concern. Therefore, there is a need for reproducibility of results before any positive finding is widely accepted.

Answers relating to areas of agreement:

- Is vitamin $\mathrm{D}_{3}$ superior to $\mathrm{D}_{2}$ ? Pharmacokinetics, clinical data.

Vitamin $\mathrm{D}_{3}$ treatment results in larger increases in serum 25OHD than does vitamin $\mathrm{D}_{2}$. In addition, the oral route of administration is more effective at rapidly increasing serum 25OHD than the intramuscular route, with a 2-month lag time for the latter.

- What is the role for 25-hydroxyvitamin D (calcidiol) in replacement and its availability?

In patients with advanced liver disease in whom the hepatic hydroxylation of vitamin D is impaired, calcidiol would be a logical form because it bypasses that hydroxylation step in the liver, as it is in the setting of glucocorticoid-induced inhibition of hepatic 25-hydroxylase. Calcidiol is more effective in increasing serum 25OHD than vitamin D.

- Is there a place for active vitamin D metabolites in treating vitamin deficiency?

The use of calcitriol or alfacalcidol is recommended only in patients with renal insufficiency and secondary hyperparathyroidism in whom renal $1 \alpha$-hydroxylation of vitamin D is impaired. However, even in this clinical setting, there is some evidence that native vitamin $\mathrm{D}$ has the capability to normalize serum parathyroid hormone values, at least when the hyperparathyroidism is not severe. Hypercalciuria and hypercalcaemia may complicate therapy with active vitamin D metabolites.

- Is daily dosing of vitamin D preferred to larger weekly, monthly or annual doses?

After 3 months, daily or equivalent monthly doses of vitamin $\mathrm{D}_{3}$ achieved the same serum 25OHD concentrations. However, avoiding large annual or monthly doses of vitamin $\mathrm{D}$ is recommended in the 
elderly, in whom an increased risk of falling has been reported with bolus dosing.

- Does the baseline level of serum 25-hydroxyvitamin D influence the choice and frequency of dose?

Supplementation with vitamin D increases serum 25-hydroxyvitamin $\mathrm{D}$ levels, but the increment depends upon the baseline serum 25-hydroxyvitamin D concentration. Lower baseline serum 25-hydroxyvitamin D levels are associated with larger increases in serum 25-hydroxyvitamin $\mathrm{D}$ for a given dose of vitamin $\mathrm{D}$. Loading doses may be considered in severe vitamin D deficiency. A total loading dose of 30-40 000 IU of vitamin $\mathrm{D}_{3}$ should be sufficient to replace near total absence of vitamin $\mathrm{D}$ to normal 25-hydroxyvitamin D concentrations $(50-75 \mathrm{nmol} / \mathrm{L})$.

- Does BMI or race influence the dose or mode of administration?

Body weight affects the serum 25-hydroxyvitamin $\mathrm{D}$ response to both loading and maintenance doses of vitamin D, with larger doses being required. Compared to Caucasians, blacks have lower total 25-hydroxyvitamin D levels attributed primarily to lower cutaneous biosynthesis. Individuals from Saudi Arabia and China are also more likely to have vitamin $\mathrm{D}$ deficiency and may require higher doses of vitamin D initially, but there are no ethnic differences in the dose response to vitamin D.

- What is the role of fortification in increasing vitamin D?

While food fortification practices are modifying the epidemiological surveys of vitamin D status throughout the world, it is unrealistic to expect that such measures alone will satisfy recommended daily vitamin D requirements across all populations. Therefore, the use of vitamin D supplements is often required to ensure normal vitamin D status.

- How much is too much vitamin D?

Vitamin D is very safe. However, the most frequent cause of vitamin D overdosing is exogenous, with extremely high doses (e.g. $50000 \mathrm{IU}$ given per day instead of per week) and consequent production of very high levels of serum 25-hydroxyvitamin D (>250 nmol/L). Symptoms of hypercalcaemia may be present and often take a long time to remit in view of the prolonged half-life of vitamin $\mathrm{D}$.
- What adverse outcomes are important?

A recently recognized adverse consequence of excessive exogenous vitamin D dosing is an increased risk of fracture and falls observed in the elderly when large, 'bolus' doses of vitamin $\mathrm{D}$ are employed. This form of excessive vitamin $\mathrm{D}$ is not accompanied by changes in serum or urine calcium concentrations. The relationship between vitamin $\mathrm{D}$ and mortality is biphasic, with an increased mortality observed under both vitamin D insufficiency and excess.

\section{Research agenda}

Variables that influence dosing and levels:

1. Is there a race $\times$ vitamin $D$ supplementation interaction on extra-skeletal outcomes (such as CVD, diabetes, cancer)?

2. How does body composition influence 25-hydroxyvitamin D level after supplementation with vitamin $\mathrm{D}$ and during weight loss?

3. Do different types of weight loss (medical, surgical) affect 25 -hydroxyvitamin D level differently?

Extra-skeletal effects:

1. What is the effect of long-term daily vitamin D supplementation on non-skeletal outcomes, such as T2DM, cancer and CVD?

2. What is the optimal dose and serum level that balances extra-skeletal benefits (e.g. T2DM) vs risks (e.g., CVD)?

Primary hyperparathyroidism:

1. How will the epidemiology of clinical presentations of PHPT change as many countries begin to screen the population with serum calcium measurements?

2. Are low levels of vitamin D in the asymptomatic variant of PHPT associated with microstructural skeletal abnormalities, along with higher PTH levels?

3. As generally higher levels of vitamin D in PHPT have become apparent, will the clinical phenotype of asymptomatic PHPT change?

Hypoparathyroidism:

1. What is the natural history of hypoparathyroidism with or without rhPTH(1-84)?

2. What delivery systems or administration protocols will reduce urinary calcium in hypoparathyroidism?

3. How will reductions in vitamin $\mathrm{D}$ needs with rhPTH(1-84) lead to improved skeletal health and 
a reduction in concerns about target and off target organ calcifications?

4. Will rhPTH(1-84) and subsequent reduction in need for vitamin D also improve the outlook for renal function in hypoparathyroidism?

Randomized controlled clinical trials:

1. Will the large ongoing vitamin D RCTs be able to determine if effects of supplementation are greatest in those individuals with the lowest serum 25-hydroxyvitamin D levels ( $<30 \mathrm{nmol} / \mathrm{L})$ ?

2. Will the large number of secondary outcomes in these large RCTs increase the risk for false negative results?

\section{Declaration of interest}

$P R E$ has received research funding or honoraria from Amgen, Eli-Lilly, Gilead and Sanofi. S M served as a speaker for Abiogen-Pharma, Amgen, Bruno Farmaceutici, Diasorin, Eli-Lilly, Fujii. He also served in advisory board of Abiogen-Pharma and as a consultant for Bruno Farmaceutici. N N has been a consultant for Abiogen-Pharma. A G has been a consultant for Abiogen-Pharma, Astellas, Ipsen, Novartis, Pfizer, Shire. R R has received honoraria for advisory board or lectures from Mylan, Radius Health, CNIEL, Effryx, Sandoz. R A A, G J, U A L, C F M, G M, A G P and J P B declare no conflict of interest.

\section{Funding}

The First International Conference on Controversies on Vitamin D was supported by an unrestricted educational grant from the Abiogen-Pharma company.

\section{References}

1 Webb AR. Who, what, where and when-influences on cutaneous vitamin D synthesis. Progress in Biophysics and Molecular Biology 2006 92 17-25. (https://doi.org/10.1016/j.pbiomolbio.2006.02.004)

2 Farrar MD, Mughal MZ, Adams JE, Wilkinson J, Berry JL, Edwards L, Kift R, Marjanovic E, Vail A, Webb AR et al. Sun exposure behavior, seasonal vitamin $\mathrm{D}$ deficiency, and relationship to bone health in adolescents. Journal of Clinical Endocrinology and Metabolism 2016101 3105-3113. (https://doi.org/10.1210/jc.2016-1559)

3 O'Neill CM, Kazantzidis A, Ryan MJ, Barber N, Sempos CT, DurazoArvizu RA, Jorde R, Grimnes G, Eiriksdottir G, Gudnason V et al. Seasonal changes in vitamin D-effective UVB availability in Europe and associations with population Serum 25-hydroxyvitamin D. Nutrients 201630 E533. (https://doi.org/10.3390/nu8090533)

4 Vierucci F, Del Pistoia M, Fanos M, Erba P \& Saggese G. Prevalence of hypovitaminosis D and predictors of vitamin D status in Italian healthy adolescents. Italian Journal of Pediatrics 201440 54. (https:// doi.org/10.1186/1824-7288-40-54)

5 Cashman KD \& Kiely M. Tackling inadequate vitamin D intakes within the population: fortification of dairy products with vitamin D may not be enough. Endocrine 201651 38-46. (https://doi. org/10.1007/s12020-015-0711-x)

6 Black LJ, Seamans KM, Cashman KD \& Kiely M. An updated systematic review and meta-analysis of the efficacy of vitamin D food fortification. Journal of Nutrition 2012142 1102-1108. (https://doi. org/10.3945/jn.112.158014)
7 Odin, food-based solutions for eradication of vitamin D deficiency and health promotion throughout the life-cycle. (available at: http:// www.odin-vitd.eu)

8 Enhanced meats and eggs' project website. (available at: http://www. ucc.ie/en/vitamind/history/ongoing/enhancedmeats)

9 Holick MF, Binkley NC, Bischoff-Ferrari HA, Gordon CM, Hanley DA, Heaney RP, Murad MH, Weaver CM \& Endocrine Society. Evaluation, treatment, and prevention of vitamin D deficiency: an Endocrine Society Clinical Practice Guideline. Journal of Clinical Endocrinology and Metabolism 201196 1911-1930. (https://doi.org/10.1210/ jc.2011-0385)

10 Bischoff-Ferrari HA. Which vitamin D oral supplement is best for postmenopausal women? Current Osteoporosis Reports 201210 251-257. (https://doi.org/10.1007/s11914-012-0118-z)

11 Tripkovic L, Wilson LR, Hart K, Johnsen S, de Lusignan S, Smith CP, Bucca G, Penson S, Chope G, Elliott R et al. Daily supplementation with $15 \mu \mathrm{g}$ vitamin D2 compared with vitamin D3 to increase wintertime 25-hydroxyvitamin D status in healthy South Asian and white European women: a 12-wk randomized, placebo-controlled food-fortification trial. American Journal of Clinical Nutrition 2017106 481-490. (https://doi.org/10.3945/ajcn.116.138693)

12 Bischoff-Ferrari HA, Willett WC, Wong JB, Stuck AE, Staehelin HB, Orav EJ, Thoma A, Kiel DP \& Henschkowski J. Prevention of nonvertebral fractures with oral vitamin $\mathrm{D}$ and dose dependency: a meta-analysis of randomized controlled trials. Archives of Internal Medicine 2009169 551-561. (https://doi.org/10.1001/ archinternmed.2008.600)

13 Avenell A, Mak JC \& O'Connell D. Vitamin D and vitamin D analogues for preventing fractures in post-menopausal women and older men. Cochrane Database of Systematic Reviews 201414 CD000227. (https://doi.org/10.1002/14651858.CD000227.pub4)

14 Cianferotti L, Cricelli C, Kanis JA, Nuti R, Reginster JY, Ringe JD, Rizzoli R \& Brandi ML. The clinical use of vitamin D metabolites and their potential developments: a position statement from the European Society for Clinical and Economic Aspects of Osteoporosis and Osteoarthritis (ESCEO) and the International Osteoporosis Foundation (IOF). Endocrine 201550 12-26. (https://doi.org/10.1007/ s12020-015-0606-X)

15 Ortego-Jurado M, Callejas-Rubio JL, Ríos-Fernández R, GonzálezMoreno J, González Ramírez AR, González-Gay MA \& OrtegoCenteno N. Oral calcidiol is more effective than cholecalciferol supplementation to reach adequate $25(\mathrm{oh}) \mathrm{d}$ levels in patients with autoimmune diseases chronically treated with low doses of glucocorticoids: a 'real-life' study. Journal of Osteoporosis 20152015 729451. (https://doi.org/10.1155/2015/729451)

16 Ringe JD, Dorst A, Faber H, Schacht E \& Rahlfs VW. Superiority of alfacalcidol over plain vitamin D in the treatment of glucocorticoidinduced osteoporosis. Rheumatology International 200424 63-70. (https://doi.org/10.1007/s00296-003-0361-9)

17 Richy F, Schacht E, Bruyere O, Ethgen O, Gourlay M \& Reginster JY. Vitamin D analogs versus native vitamin D in preventing bone loss and osteoporosis-related fractures: a comparative meta-analysis. Calcified Tissue International 200576 176-186. (https://doi. org/10.1007/s00223-004-0005-4)

18 Ebeling PR, Wark JD, Yeung S, Poon C, Salehi N, Nicholson GC $\&$ Kotowicz MA. Effects of calcitriol or calcium on bone mineral density, bone turnover, and fractures in men with primary osteoporosis: a two-year randomized, double blind, double placebo study. Journal of Clinical Endocrinology and Metabolism 200186 4098-4103. (https://doi.org/10.1210/jcem.86.9.7847)

19 Kandula P, Dobre M, Schold JD, Schreiber MJ Jr, Mehrotra R \& Navaneethan SD. Vitamin D supplementation in chronic kidney disease: a systematic review and meta-analysis of observational studies and randomized controlled trials. Clinical Journal of the American Society of Nephrology 20116 50-62. (https://doi. org/10.2215/CJN.03940510) 
20 Goldsmith DJ. Pro: should we correct vitamin D deficiency/ insufficiency in chronic kidney disease patients with inactive forms of vitamin D or just treat them with active vitamin D forms? Nephrology, Dialysis, Transplantation 201631 698-705. (https://doi. org/10.1093/ndt/gfw082)

21 Institute of Medicine (IOM). Dietary Reference Intakes for Calcium and Vitamin D. Washington, DC: National Academies Press, 2011.

22 Gallagher JC, Sai A, Templin T 2nd \& Smith L. Dose response to vitamin D supplementation in postmenopausal women: a randomized trial. Annals of Internal Medicine 2012156 425-437. (https://doi.org/10.7326/0003-4819-156-6-201203200-00005)

23 Ceglia L, Nelson J, Ware J, Alysandratos KD, Bray GA, Garganta C, Nathan DM, Hu FB, Dawson-Hughes B, Pittas AG et al. Diabetes prevention program research $\mathrm{G}$. Association between body weight and composition and plasma 25-hydroxyvitamin D level in the Diabetes Prevention Program. European Journal of Nutrition 201756 161-170. (https://doi.org/10.1007/s00394-015-1066-z)

24 King RJ, Chandrajay D, Abbas A, Orme SM \& Barth JH. High-dose oral colecalciferol loading in obesity: impact of body mass index and its utility prior to bariatric surgery to treat vitamin D deficiency. Clinical Obesity 20177 92-97. (https://doi.org/10.1111/cob.12176)

25 van Groningen L, Opdenoordt S, van Sorge A, Telting D, Giesen A $\&$ de Boer H. Cholecalciferol loading dose guideline for vitamin D-deficient adults. European Journal of Endocrinology 2010162 805-811. (https://doi.org/10.1530/EJE-09-0932)

26 Sanders KM, Stuart AL, Williamson EJ, Simpson JA, Kotowicz MA, Young D \& Nicolson GC. Annual high-dose oral vitamin D and falls and fractures in older women: a randomized controlled trial. JAMA 2010303 1815-1822. (https://doi.org/10.1001/jama.2010.594)

27 Bischoff-Ferrari HA, Dawson-Hughes B, Orav EJ, Staehelin HB, Meyer OW, Theiler R, Dick W, Willett WC \& Egli A. Monthly highdose vitamin $\mathrm{D}$ treatment for the prevention of functional decline: a randomized clinical trial. JAMA Internal Medicine 2016176 175-183. (https://doi.org/10.1001/jamainternmed.2015.7148)

28 Romagnoli E, Mascia ML, Cipriani C, Fassino V, Mazzei F, D'Erasmo E, Carnevale V, Scillitani A \& Minisola S. Short and longterm variations in serum calciotropic hormones after a single very large dose of ergocalciferol (vitamin D2) or cholecalciferol (vitamin D3) in the elderly. Journal of Clinical Endocrinology and Metabolism 200893 3015-3020. (https://doi.org/10.1210/jc.2008-0350)

29 Ish-Shalom S, Segal E, Salganik T, Raz B, Bromberg IL \& Vieth R. Comparison of daily, weekly, and monthly vitamin D3 in ethanol dosing protocols for two months in elderly hip fracture patients. Journal of Clinical Endocrinology and Metabolism 200893 3430-3435. (https://doi.org/10.1210/jc.2008-0241)

30 Vieth R, Chan PC \& MacFarlane GD. Efficacy and safety of vitamin D3 intake exceeding the lowest observed adverse effect level. American Journal of Clinical Nutrition 200173 288-294. (https://doi. org/10.1093/ajcn/73.2.288)

31 Binkley N, Gemar D, Engelke J, Gangnon R, Ramamurthy R, Krueger D \& Drezner MK. Evaluation of ergocalciferol or cholecalciferol dosing, 1600 IU daily or 50000 IU monthly in older adults. Journal of Clinical Endocrinology and Metabolism 201196 981-988. (https://doi.org/10.1210/jc.2010-0015)

32 Tripkovic L, Lambert H, Hart K, Smith CP, Bucca G, Penson S, Chope G, Hyppönen E, Berry J, Vieth R et al. Comparison of vitamin D2 and vitamin D3 supplementation in raising serum 25-hydroxyvitamin D status: a systematic review and meta-analysis. American Journal of Clinical Nutrition 201295 1357-1364. (https:// doi.org/10.3945/ajcn.111.031070)

33 Dawson-Hughes B, Harris SS, Lichtenstein AH, Dolnikowski G, Palermo NJ \& Rasmussen H. Dietary fat increases vitamin D-3 absorption. Journal of the Academy of Nutrition and Dietetics 2015115 225-230. (https://doi.org/10.1016/j.jand.2014.09.014)

34 Gallagher JC, Peacock M, Yalamanchili V \& Smith LM. Effects of vitamin D supplementation in older African American women.
Journal of Clinical Endocrinology and Metabolism 201398 1137-1146. (https://doi.org/10.1210/jc.2012-3106)

35 Robinson-Cohen C, Hoofnagle AN, Ix JH, Sachs MC, Tracy RP, Siscovick DS, Kestenbaum BR \& de Boer IH. Racial differences in the association of serum 25-hydroxyvitamin D concentration with coronary heart disease events. JAMA 2013310 179-188. (https://doi. org/0.1001/jama.2013.7228)

36 Scragg R, Sowers M, Serum BC \& Third National Health and Nutrition Examination Survey. Serum 25-hydroxyvitamin D, diabetes, and ethnicity in the third National Health and Nutrition Examination Survey. Diabetes Care 200427 2813-2818. (https://doi. org/10.2337/diacare.27.12.2813)

37 Hwalla N, Al Dhaheri AS, Radwan H, Alfawaz HA, Fouda MA, Al-Daghri NM, Sahar Zaghloul S \& Blumberg JB. The prevalence of micronutrient deficiencies and inadequacies in the Middle East and approaches to interventions. Nutrients 20179 229. (https://doi. org/10.3390/nu9030229)

38 Yu S, Fang H, Han J, Cheng X, Xia L, Li S, Liu M, Tao Z, Wang L, Hou L et al. The high prevalence of hypovitaminosis D in China: a multicenter vitamin D status survey. Medicine 201594 e585. (https:// doi.org/10.1097/MD.0000000000000585)

39 Song Y, Wang L, Pittas AG, Del Gobbo LC, Zhang C, Manson JE \& Hu FB. Blood 25-hydroxy vitamin D levels and incident type 2 diabetes: a meta-analysis of prospective studies. Diabetes Care 2013 36 1422-1428. (https://doi.org/10.2337/dc12-0962)

40 Jorde R, Sollid ST, Svartberg J, Schirmer H, Joakimsen RM, Njolstad I, Fuskevag OM, Figenschau Y \& Hutchinson MY. Vitamin D 20000 IU per week for five years does not prevent progression from prediabetes to diabetes. Journal of Clinical Endocrinology and Metabolism 2016101 1647-1655. (https://doi. org/10.1210/jc.2015-4013)

41 Durazo-Arvizu RA, Dawson-Hughes B, Kramer H, Cao G, Merkel J, Coates PM \& Sempos CT. The reverse J-shaped association between serum total 25-hydroxyvitamin D concentration and all-cause mortality: the impact of assay standardization. American Journal of Epidemiology 2017185 720-726. (https://doi.org/10.1093/aje/ kww244)

42 Durup D, Jørgensen HL, Christensen J, Schwarz P, Heegaard AM \& Lind B. A reverse J-shaped association of all-cause mortality with serum 25-hydroxyvitamin D in general practice: the CopD study. Journal of Clinical Endocrinology and Metabolism 201297 2644-2652. (https://doi.org/10.1210/jc.2012-1176)

43 Rizzoli R, Stoermann C, Ammann P \& Bonjour JP. Hypercalcemia and hyperosteolysis in vitamin D intoxication: effects of clodronate therapy. Bone 199415 193-198. (https://doi.org/10.1016/87563282(94)90707-2)

44 Wani M, Wani I, Banday K \& Ashraf M. The other side of vitamin D therapy: a case series of acute kidney injury due to malpracticerelated vitamin D intoxication. Clinical Nephrology 201686 236-241. (https://doi.org/10.5414/CN108904)

45 Smith LM, Gallagher JC \& Suiter C. Medium doses of daily vitamin $\mathrm{D}$ decrease falls and higher doses of daily vitamin D3 increase falls: a randomized clinical trial. Journal of Steroid Biochemistry and Molecular Biology 2017173 317-322. (https://doi.org/10.1016/j. jsbmb.2017.03.015)

46 Locker FG, Silverberg SJ \& Bilezikian JP. Levels of 1,25-dihydroxyvitamin $\mathrm{D}$ in primary hyperparathyroidism may help to guide recommendations for dietary calcium intake. Journal of Bone and Mineral Research 199510 S599.

47 Silverberg SJ, Shane E, Dempster DW \& Bilezikian JP. Vitamin D insufficiency in primary hyperparathyroidism. American Journal of Medicine 1999107 561-567. (https://doi.org/10.1016/S00029343(99)00294-6)

48 Walker MD \& Bilezikian JP. Vitamin D and primary hyperparathyroidism: more insights into a complex relationship. Endocrine 201755 3-5. (https://doi.org/10.1007/s12020-016-1169-1) 
49 Bilezikian JP. Primary hyperparathyroidism. In www.ENDOTEXT.org (Version of 2017). Eds L DeGroot \& F Singer. MA: MDTEXT.COM, Inc, Dartmouth Publishing, 2017.

50 Stein EM, Dempster DW, Udesky J, Zhou H, Bilezikian JP, Shane E \& Silverberg SJ. Vitamin D deficiency influences histomorphometric features of bone in primary hyperparathyroidism. Bone 20111 557-561. (https://doi.org/10.1016/j.bone.2010.10.004)

51 Walker MD, Cong E, Lee JA, Kepley A, Zhang C, McMahon DJ \& Silverberg SJ. Vitamin D in primary hyperparathyroidism: effects on clinical, biochemical, and densitometric presentation. Journal of Clinical Endocrinology and Metabolism 2015100 3443-3451. (https:// doi.org/10.1210/jc.2015-2022)

52 Walker MD, Saeed I, Lee JA, Zhang C, Hans D, Lang T \& Silverberg SJ. Effect of concomitant vitamin D deficiency or insufficiency on lumbar spine volumetric bone mineral density and trabecular bone score in primary hyperparathyroidism. Osteoporosis International 2016 27 3063-3071. (https://doi.org/10.1007/s00198-016-3637-0)

53 Walker MD, Nishiyama KK, Zhou B, Cong E, Wang J, Lee JA, Kepley A, Zhang C, Guo XE \& Silverberg SJ. Effect of low vitamin $\mathrm{D}$ on volumetric bone mineral density, bone microarchitecture, and stiffness in primary hyperparathyroidism. Journal of Clinical Endocrinology and Metabolism 2016101 905-913. (https://doi. org/10.1210/jc.2015-4218)

54 Bilezikian JP, Meng X, Shi Y \& Silverberg SJ. Primary hyperparathyroidism in women: New York and Beijing (A Tale of two Cities). International Journal of Fertility and Women's Health 200045 158-165.

55 Minisola S, Pepe J, Scillitani A \& Cipriani C. Explaining geographical variation in the presentation of primary hyperparathyroidism. Lancet Diabetes and Endocrinology 20164 641-643. (https://doi.org/10.1016/ S2213-8587(16)00076-0)

56 Walker MD, Cong E, Lee JA, Kepley A, Zhang C, McMahon DJ, Bilezikian JP \& Silverberg SJ. Low vitamin D levels have become less common in primary hyperparathyroidism. Osteoporosis International 201526 2837-2843. (https://doi.org/10.1007/s00198-015-3199-6)

57 Marcocci C, Bollerslev J, Khan AA \& Shoback DM. Medical management of primary hyperparathyroidism: Proceedings of the Fourth International Workshop on the Management of Primary Hyperparathyroidism. Journal of Clinical Endocrinology and Metabolism 201499 3607-3618. (https://doi.org/10.1210/jc.2014-1417)

58 Khan AA, Hanley DA, Rizzoli R, Bollerslev J, Young JE, Rejnmark L, Thakker R, D'Amour P, Paul T, Van Uum S et al. Primary hyperparathyroidism: review and recommendations on evaluation, diagnosis, and management. A Canadian and International Consensus. Osteoporosis International 201728 1-19. (https://doi. org/10.1007/s00198-016-3716-2)

59 Rolighed L, Rejnmark L, Sikjaer T, Heickendorff L, Vestergaard P, Mosekilde L \& Christiansen P. Vitamin D treatment in primary hyperparathyroidism: a randomized placebo controlled trial. Journal of Clinical Endocrinology and Metabolism 201499 1072-1080. (https:// doi.org/10.1210/jc.2013-3978)

60 Loh HH, Lim LL, Yee A, Loh HS \& Vethakkan SR. Effect of vitamin D replacement in primary hyperparathyroidism with concurrent vitamin D deficiency: a systematic review and meta-analysis. Minerva Endocrinology 2017. (https://doi.org/10.23736/S0391-1977.17.025846)

61 Minisola S, Romagnoli E, Scillitani A \& Rao SD. Hypovitaminosis $\mathrm{D}$ in primary hyperparathyroidism: to treat or not to treat? That is the question. Journal of Endocrinology Investigation 201437 413-414. (https://doi.org/10.1007/s40618-014-0060-2)

62 Marcocci C, Brandi ML, Scillitani A, Corbetta S, Faggiano A, Gianotti L, Migliaccio S, Minisola S. Italian Society of Endocrinology Consensus Statement: definition, evaluation and management of patients with mild primary hyperparathyroidism. Journal of Endocrinology Investigation 201538 577-593. (https://doi. org/10.1007/s40618-015-0261-3)
63 Clarke BL, Vokes TJ, Bilezikian JP, Shoback DM, Lagast H \& Mannstadt M. Effects of parathyroid hormone [rhPTH(1-84)] on phosphate homeostasis and vitamin D metabolism in hypoparathyroidism: REPLACE Phase 3 Study. Endocrine 201755 273-282. (https://doi.org/10.1007/s12020-016-1141-0)

64 Bueter M. Bariatric surgery and fractures. BMJ 2016354 i4057. (https://doi.org/10.1136/bmj.i4057)

65 Cole AJ, Beckman LM \& Earthman CP. Vitamin D status following bariatric surgery: implications and recommendations. Nutrition in Clinical Practice 201429 751-758. (https://doi. org/10.1177/0884533614546888)

66 Romagnoli E, Pepe J, Piemonte S, Cipriani C \& Minisola S. Management of endocrine disease: value and limitations of assessing vitamin D nutritional status and advised levels of vitamin D supplementation. European Journal of Endocrinology 2013169 R59-R69. (https://doi.org/10.1530/EJE-13-0435)

67 Pepe J, Cipriani C, Cilli M, Colangelo L \& Minisola S. Adipokines and bone metabolism: an interplay to untangle. Journal of Endocrinology Investigation 201639 1359-1361. (https://doi.org/10.1007/s40618016-0549-y)

68 Borges JLC, Miranda ISM, Sarquis MMS, Borba V, Maeda SS, LazarettiCastro M \& Blinkey N. Obesity, bariatric surgery, and vitamin D. Journal of Clinical Densitometry 201721 157-162. (https://doi. org/10.1016/j.jocd.2017.03.001)

69 Cipriani C, Romagnoli E, Pepe J, Russo S, Carlucci L, Piemonte S, Nieddu L, McMahon DJ, Singh R \& Minisola S. Long-term bioavailability after a single oral or intramuscular administration of $600000 \mathrm{IU}$ of ergocalciferol or cholecalciferol: implications for treatment and prophylaxis. Journal of Clinical Endocrinology and Metabolism 201398 2709-2715. (https://doi.org/10.1210/jc.20131586)

70 Romagnoli E, Mascia ML, Cipriani C, Fassino V, Mazzei F, D'Erasmo E, Carnevale V, Scillitani A \& Minisola S. Short- and longterm variations in serum calciotropic hormones after a single very large dose of ergocalciferol (vitamin $\mathrm{D}_{2}$ ) or cholecalciferol (vitamin $\mathrm{D}_{3}$ ) in the elderly. Journal of Clinical Endocrinology and Metabolism 200893 3015-3020. (https://doi.org/10.1210/jc.2008-0350)

71 Schafer AL, Weaver CM, Black DM, Wheeler AL, Chang H, Szefc GV, Stewart L, Rogers SJ, Carter JT, Posselt AM et al. Intestinal calcium absorption decreases dramatically after gastric bypass surgery despite optimization of vitamin D status. Journal of Bone and Mineral Research 201530 1377-1385. (https://doi.org/10.1002/ jbmr.2467)

72 Rousseau C, Jean S, Gamache P, Lebel S, Mac-Way F, Biertho L, Michou L \& Gagnon C. Change in fracture risk and fracture pattern after bariatric surgery: nested case-control study. BMJ 2016354 i3794. (https://doi.org/10.1136/bmj.i3794)

73 Coresh J, Byrd-Holt D, Astor BC, Briggs JP, Eggers PW, Lacher DA $\&$ Hostetter TH. Chronic kidney disease awareness, prevalence, and trends among U.S. adults, 1999 to 2000. Journal of American Society of Nephrology 200516 180-188. (https://doi.org/10.1681/ ASN.2004070539)

74 United States renal data system (USRDS). Annual data report, 2005. (available at: www.usrds.org)

75 Ketteler M, Block GA, Evenepoel P, Fukagawa M, Herzog CA, McCann L, Moe SM, Shroff R, Tonelli MA, Toussaint ND et al. Executive summary of the 2017 KDIGO Chronic Kidney DiseaseMineral and Bone Disorder (CKD-MBD) Guideline Update: what's changed and why it matters. Kidney International 201792 26-36. (https://doi.org/10.1016/j.kint.2017.04.006)

76 Pimentel A, Ureña-Torres P, Zillikens MC, Bover J \& Cohen-Solal M. Fractures in patients with CKD-diagnosis, treatment, and prevention: a review by members of the European Calcified Tissue Society and the European Renal Association of Nephrology Dialysis and Transplantation. Kidney International 201792 1343-1355. (https:// doi.org/10.1016/j.kint.2017.07.021) 
77 Schlingmann KP, Kaufmann M, Weber S, Irwin A, Goos C, John U, Misselwitz J, Klaus G, Kuwertz-Bröking E, Fehrenbach $\mathrm{H}$ et al. Mutations in CYP24A1 and idiopathic infantile hypercalcaemia. New England Journal of Medicine 2011365 410-421. (https://doi. org/10.1056/NEJMoa1103864)

78 Schlingmann KP, Ruminska J, Kaufmann M, Dursun I, Patti M, Kranz B, Pronicka E, Ciara E, Akcay T, Bulus D et al. Autosomalrecessive mutations in SLC34A1 encoding sodium-phosphate cotransporter $2 \mathrm{~A}$ cause idiopathic infantile hypercalcemia. Journal of the American Society of Nephrology 201627 604-614. (https://doi. org/10.1681/ASN.2014101025)

79 Molin A, Baudoin R, Kaufmann M, Souberbielle JC, Ryckewaert A, Vantyghem MC, Eckart P, Bacchetta J, Deschenes G, Kesler-Roussey G et al. CYP24A1 mutations in a cohort of hypercalcemic patients: evidence for a recessive trait. Journal of Clinical Endocrinology and Metabolism 2015100 E1343-E1352. (https://doi.org/10.1210/jc.20144387)

80 Nesterova G, Malicdan MC, Yasuda K, Sakaki T, Vilboux T, Ciccone C, Horst R, Huang Y, Golas G, Introne W et al. 1,25-(OH)2D-24 hydroxylase (CYP24A1) deficiency as a cause of nephrolithiasis. Clinical Journal of the American Society of Nephrology 20138 649-657. (https://doi.org/10.2215/CJN.05360512)

81 Kaufmann M, Gallagher JC, Peacock M, Schlingmann KP, Konrad M, DeLuca HF, Sigueiro R, Lopez B, Mourino A, Maestro M et al. Clinical utility of simultaneous quantitation of 25-hydroxyvitamin D and 24,25-dihydroxyvitamin D by LC-MS/MS involving derivatization with DMEQ-TAD. Journal of Clinical Endocrinology and Metabolism 201499 2567-2574. (https://doi.org/10.1210/jc.2013-4388)

82 Kaufmann M, Morse N, Molloy BJ, Cooper DP, Schlingmann KP, Molin A, Kottler ML, Gallagher JC, Armas L \& Jones G. Improved screening test for idiopathic infantile hypercalcemia confirms residual levels of Serum 24,25-(OH)2 D3 in affected patients. Journal of Bone and Mineral Research 201732 1589-1596. (https://doi. org/10.1002/jbmr.3135)

83 Tai SS, Nelson MA, Bedner M, Lang BE, Phinney KW, Sander LC, Yen JH, Betz JM, Sempos CT \& Wise SA. Development of standard reference material (SRM) 2973 vitamin D metabolites in frozen human serum (high level). Journal of AOAC International $2017 \mathbf{1 0 0}$ 1294-1303. (https://doi.org/10.5740/jaoacint.17-0182)

84 Munns CF, Shaw N, Kiely M, Specker BL, Thacher TD, Ozono K, Michigami T, Tiosano D, Mughal MZ, Mäkitie O et al. Global consensus recommendations on prevention and management of nutritional rickets. Journal of Clinical Endocrinology and Metabolism 2016101 394-415. (https://doi.org/10.1210/jc.2015-2175)

85 Liberman UA, Samuel R, Halabe A, Kauli R, Edelstein S, Weisman Y, Papapoulos SE, Clemens TL, Fraher LJ \& O'Riordan JL. Disorders in vitamin D action. In Diseases of Bone and Mineral Metabolism. Ed F Singer, 2014.

86 Malloy PJ, Pike JW \& Feldman D. Hereditary 1,25-dihydroxyvitamin D resistant rickets. In Vitamin D, 2nd ed. Eds D Feldman, JW Pike \& FH Glorieux. San Diego, CA, USA: Elsevier Academic Press, 2005.

87 Liberman UA. Hereditary deficiencies in vitamin D action. In Principles of Bone Biology, 3rd ed. Eds JP Bilezikian, LG Raisz \& TG Martin. San Diego, CA, USA: Elsevier Academic Press, 2008.

88 Liberman UA \& Marx SJ. Vitamin D and other calciferols. In The Metabolic and Molecular Basis of Inherited Diseases, 8th ed. Eds CR Scriver, AL Beaudet, WS Sly \& D Valle. New York: McGraw Hill, 2001.

89 Whyte MP \& Liberman UA. Rickets and osteomalacia (acquired and heritable forms). In Oxford Textbook of Endocrinology and Diabetes, 4th ed. Eds JAH Wass, PM Stewart, SA Amiel \& MC Davies, 2011.

90 Thacher TD \& Levine MA. CYP2R1 mutations causing vitamin D-deficiency rickets. Journal of Steroid Biochemistry and Molecular Biology 2017173 333-336. (https://doi.org/10.1016/j. jsbmb.2016.07.014)

91 Bolland MJ, Grey A, Gamble GD \& Reid IR. Vitamin D supplementation and falls: a trial sequential meta-analysis. Lancet
Diabetes and Endocrinology 20142 573-580. (https://doi.org/10.1016/ S2213-8587(14)70068-3)

92 Gillespie LD, Robertson MC, Gillespie WJ, Sherrington C, Gates S, Clemson LM \& Lamb SE. Interventions for preventing falls in older people living in the community. Cochrane Database of Systematic Reviews 201212 CD007146. (https://doi.org/10.1002/14651858. CD007146.pub3)

93 Witham MD, Price RJ, Struthers AD, Donnan PT, Messow CM, Ford I $\&$ McMurdo ME. Cholecalciferol treatment to reduce blood pressure in older patients with isolated systolic hypertension: the VitDISH randomized controlled trial. JAMA Internal Medicine $2013 \mathbf{1 7 3}$ 1672-1679. (https://doi.org/10.1001/jamainternmed.2013.9043)

94 Scragg R, Stewart AW, Waayer D, Lawes CMM, Toop L, Sluyter J, Murphy J, Khaw KT \& Camargo CA Jr. Effect of monthly high-dose vitamin D supplementation on cardiovascular disease in the vitamin D assessment study (ViDA). JAMA Cardiology 20172 608-616. (https://doi.org/10.1001/jamacardio.2017.0175)

95 Cooper C, Harvey NC, Bishop NJ, Kennedy S, Papageorghiou AT, Schoenmakers I, Fraser R, Gandhi SV, Carr A, D'Angelo S et al. Maternal gestational vitamin $\mathrm{D}$ supplementation and offspring bone health (MAVIDOS): a multicentre, double-blind, randomised placebo-controlled trial. Lancet Diabetes and Endocrinology 20164 393-402. (https://doi.org/10.1016/S2213-8587(16)00044-9)

96 Khaw KT, Stewart AW, Waayer D, Lawes CMM, Toop L, Camargo CA Jr \& Scragg R. Effect of monthly high-dose vitamin D supplementation on falls and non-vertebral fractures: secondary and post-hoc outcomes from the randomised, double-blind, placebocontrolled ViDA trial. Lancet Diabetes and Endocrinology 20175 438-447. (https://doi.org/10.1016/S2213-8587(17)30103-1)

97 Zhao JG, Zeng XT, Wang J \& Liu L. Association between calcium or vitamin $\mathrm{D}$ supplementation and fracture incidence in communitydwelling older adults: a systematic review and meta-analysis. JAMA 2017318 2466-2482. (https://doi.org/10.1001/jama.2017.19344)

98 Mason C, Tapsoba JD, Duggan C, Imayama I, Wang CY, Korde L \& McTiernan A. Effects of vitamin D3 supplementation on lean mass, muscle strength, and bone mineral density during weight loss: a double-blind randomized controlled trial. Journal of the American Geriatric Society 201664 769-778. (https://doi.org/10.1111/jgs.14049)

99 Krul-Poel YHM, Westra S, Boekel ET, ter Wee MM, van Schoor NM, van Wijland H, Stam F, Lips PT \& Simsek S. Effect of vitamin D supplementation on glycemic control in patients with type 2 diabetes (SUNNY Trial): a randomized placebo-controlled trial. Diabetes Care 201538 1420-1426. (https://doi.org/10.2337/dc150323)

100 Lappe J, Watson P, Travers-Gustafson D, Recker R, Garland C, Gorham E, Baggerly K \& McDonnell SL. Effect of vitamin D and calcium supplementation on cancer incidence in older women: a randomized clinical trial. JAMA 2017317 1234-1243. (https://doi. org/10.1001/jama.2017.2115)

101 Vuichard Gysin D, Dao D, Gysin CM, Lytvyn L \& Loeb M. Effect of vitamin D3 supplementation on respiratory tract infections in healthy individuals: a systematic review and meta-analysis of randomized controlled trials. PLoS ONE 201611 e0162996. (https:// doi.org/10.1371/journal.pone.0162996)

102 Martineau AR, Jolliffe DA, Hooper RL, Greenberg L, Aloia JF, Bergman P, Dubnov-Raz G, Esposito S, Ganmaa D, Ginde AA et al. Vitamin D supplementation to prevent acute respiratory tract infections: systematic review and meta-analysis of individual participant data. BMJ 2017356 i6583. (https://doi.org/10.1136/bmj. i6583)

103 Jin X, Jones G, Cicuttini F, Wluka A, Zhu Z, Han W, Antony B, Wang X, Winzenberg T, Blizzard L et al. Effect of vitamin D supplementation on tibial cartilage volume and knee pain among patients with symptomatic knee osteoarthritis: a randomized clinical trial. JAMA 2016315 1005-1013. (https://doi.org/10.1001/ jama.2016.1961) 
104 McAlindon T, LaValley M, Schneider E, Nuite M, Lee JY, Price LL, Lo G \& Dawson-Hughes B. Effect of vitamin D supplementation on progression of knee pain and cartilage volume loss in patients with symptomatic osteoarthritis: a randomized controlled trial. JAMA 2013309 155-162. (https://doi.org/10.1001/ jama.2012.164487)

105 Diao N, Yang B \& Yu F. Effect of vitamin D supplementation on knee osteoarthritis: a systematic review and meta-analysis of randomized clinical trials. Clinical Biochemistry 201750 1312-1316. (https://doi. org/0.1016/j.clinbiochem.2017.09.001)

106 Gao XR, Chen YS \& Deng W. The effect of vitamin D supplementation on knee osteoarthritis: a meta-analysis of randomized controlled trials. International Journal of Surgery 201746 14-20. (https://doi.org/10.1016/j.ijsu.2017.08.010)

107 Kahwati LC, Weber RP, Pan H, Gourlay M, LeBlanc E, CokerSchwimmer M \& Viswanathan M. Vitamin D, calcium, or combined supplementation for the primary prevention of fractures in community-dwelling adults: evidence report and systematic review for the US Preventive Services Task Force. JAMA 2018319 1600-1612. (https://doi.org/10.1001/jama.2017.21640)

108 US Preventive Services Task Force, Grossman DC, Curry SJ, Owens DK, Barry MJ, Caughey AB, Davidson KW, Doubeni CA, Epling JW, Kemper AR et al. Interventions to prevent falls in community-dwelling older adults: US Preventive Services Task Force Recommendation Statement. JAMA 2018319 1696-1704. (https:// doi.org/10.1001/jama.2018.3097)

109 Bolland MJ \& Avenell A. Do vitamin D supplements help prevent respiratory tract infections? BMJ 2017356 j456. (https://doi. org/10.1136/bmj.j456)

110 Pittas AG, Dawson-Hughes B, Sheehan PR, Rosen CJ, Ware JH, Knowler WC, Staten MA \& D2d Research Group. Rationale and design of the vitamin D and Type 2 Diabetes (D2d) study: a diabetes prevention trial. Diabetes Care 201437 3227-3234. (https://doi. org/10.2337/dc14-1005)

111 Manson JE, Bassuk SS, Lee IM, Cook NR, Albert MA, Gordon D, Zaharris E, Macfadyen JG, Danielson E, Lin J et al. The vitamin D and
OmegA-3 TriaL (VITAL): rationale and design of a large randomized controlled trial of vitamin D and marine omega-3 fatty acid supplements for the primary prevention of cancer and cardiovascular disease. Contemporary Clinical Trials 201233 159-171. (https://doi. org/10.1016/j.cct.2011.09.009)

112 Neale RE, Armstrong BK, Baxter C, Duarte Romero B, Ebeling P, English DR, Kimlin MG, McLeod DS, O Connell RL, van der Pols JC et al. The D-Health Trial: a randomized trial of vitamin D for prevention of mortality and cancer. Contemporary Clinical Trials 2016 48 83-90. (https://doi.org/10.1016/j.cct.2016.04.005)

113 Jackson RD, LaCroix AZ, Gass M, Wallace RB, Robbins J, Lewis CE, Bassford T, Beresford SA, Black HR, Blanchette P et al. Calcium plus vitamin D supplementation and the risk of fractures. New England Journal of Medicine 2006354 669-683. (https://doi.org/10.1056/ NEJMoa055218)

114 Grant AM, Avenell A, Campbell MK, McDonald AM, MacLennan GS, McPherson GC, Anderson FH, Cooper C, Francis RM, Donaldson C et al. Oral vitamin D3 and calcium for secondary prevention of low-trauma fractures in elderly people (Randomised Evaluation of calcium or vitamin D, RECORD): a randomised placebo-controlled trial. Lancet 2005365 1621-1628. (https://doi.org/10.1016/S01406736(05)63013-9)

115 Kawahara T, Suzuki G, Inazu T, Mizuno S, Kasagi F, Okada Y \& Tanaka Y. Rationale and design of diabetes prevention with active vitamin D (DPVD): a randomised, double-blind, placebo-controlled study. BMC Open 20166 e011183. (https://doi.org/10.1136/ bmjopen-2016-011183)

116 Vitamin D3 - Omega3 - Home Exercise - Healthy Ageing and Longevity Trial, DO-HEALTH. (available at: http://do-health.eu/ wordpress/)

117 Finnish Vitamin D (FIND). (available at: http://www.uef.fi/en/web/dvitamiini)

118 TIPS-3 - The International Polycap Study, vol. 3. the international polycap study 3 (tips-3).

119 The vitamin D and longevity trial (VIDAL) feasibility. (available at: http://vidal.lshtm.ac.uk/home/)

Received 1 March 2018

Revised version received 13 August 2018

Accepted 21 August 2018 